\title{
Histamine and Its Receptors Modulate Temperature- Preference Behaviors in Drosophila
}

\author{
Sung-Tae Hong, Sunhoe Bang, Donggi Paik, Jongkyun Kang, Seungyoon Hwang, Keunhye Jeon, Bumkoo Chun, \\ Seogang Hyun, Youngseok Lee, and Jaeseob Kim \\ Department of Biological Sciences, Korea Advanced Institute of Science and Technology, Daejeon 305-701, Korea
}

\begin{abstract}
Temperature profoundly influences various life phenomena, and most animals have developed mechanisms to respond properly to environmental temperature fluctuations. To identify genes involved in sensing ambient temperature and in responding to its change, $>27,000$ independent P-element insertion mutants of Drosophila were screened. As a result, we found that defects in the genes encoding for proteins involved in histamine signaling [histidine decarboxylase $(h d c)$, histamine-gated chloride channel subunit 1 (hisCl1), ora transientless (ort)] cause abnormal temperature preferences. The abnormal preferences shown in these mutants were restored by genetic and pharmacological rescue and could be reproduced in wild type using the histamine receptor inhibitors cimetidine and hydroxyzine. Spatial expression of these genes was observed in various brain regions including pars intercerebralis, fan-shaped body, and circadian clock neurons but not in ITRPA1-expressing neurons, an essential element for thermotaxis. We also found that the histaminergic mutants showed reduced tolerance for high temperature and enhanced tolerance for cold temperature. Together, these results suggest that histamine signaling may have important roles in modulating temperature preference and in controlling tolerance of low and high temperature.
\end{abstract}

Key words: histamine; hisCl1; ort; Drosophila; temperature; preference

\section{Introduction}

Animals are able to track suitable temperature for survival and maintain body temperature. Because of a large surface area-tovolume ratio, the body temperature of small poikilotherms like fruit flies is easily affected by the surrounding environment (Sayeed and Benzer, 1996; Zars, 2001). To counter harmful effects of environmental temperature fluctuations, molecular and behavioral mechanisms are coordinated to maintain proper body temperature for survival.

Many studies on thermotaxis/temperature preference have been performed in model organisms (Sayeed and Benzer, 1996; Mori, 1999; Zars, 2003). However, the molecular mechanisms mediating temperature preference are poorly understood. Caenorhabditis elegans is the most studied model system for temperature preference. Cell ablation studies and calcium imaging techniques were used to demonstrate that the neuronal circuitry is involved in thermotactic behavior, and genetic screens have further identified several thermotactic genes (Mori, 1999; Samuel et al., 2003; Kimura et al., 2004). In vertebrates, the preoptic area (POA) was discovered as a temperature-regulating center (Bou-

Received Dec. 20, 2005; revised May 26, 2006; accepted May 26, 2006.

This work was supported by grants from the Cell and Molecular BioDiscovery Program and the Brain Research Center of the 21st Century Frontier Program funded by the Korean Ministry of Science and Technology. We thankW Pak for providing $h d \mathrm{c}^{\mathrm{J}}{ }^{\mathrm{9} 10}$ and ort ${ }^{\mathrm{P} 306}$ fly stocks, P. Garrity for dTRPA1-Gal4 stock, and C. Kim, J. Park, and J. Chung for help in manuscript preparation.

Correspondence should be addressed to Dr. Jaeseob Kim, Department of Biological Sciences, Korea Advanced Institute of Science and Technology, 373-1 Guseong-dong, Yuseong, Daejeon 305-701, Korea (South). E-mail: kjaeseob@kaist.ac.kr.

DOI:10.1523/JNEUROSCI.5426-05.2006

Copyright $\odot 2006$ Society for Neuroscience $\quad$ 0270-6474/06/267245-12\$15.00/0 lant, 2000). In Drosophila, several temperature-sensing genes including dTRPA1, Painless, Hsp70, and Pyrexia have been characterized recently (Goto and Kimura, 1998; Tracey et al., 2003; Lee et al., 2005; Overgaard et al., 2005; Rosenzweig et al., 2005).

Histamine is a biogenic amine synthesized from L-histidine via a single decarboxylation step by histidine decarboxylase $(h d c)$ (Burg et al., 1993). In invertebrates, histamine has various roles in neurotransmission in the brain, such as olfaction in crustaceans and photoreception in various arthropods (Hardie, 1989; McClintock and Ache, 1989; Stuart, 1999), as well as in mechanoreception (Melzig et al., 1996). The histaminergic system in the vertebrate CNS projects its neurites to most regions in the brain and plays a key role in the regulation of basic body functions. Until recently, all histamine receptors identified in vertebrates were merely known as G-protein-coupled receptors (termed $\mathrm{H}_{1}$, $\mathrm{H}_{2}, \mathrm{H}_{3}$, and $\mathrm{H}_{4}$ ) (Haas and Panula, 2003). Immunohistochemical studies indicated the presence of histamine in a variety of neuron types in the brain and optic lobes, as well as in the ganglia of the ventral nerve cord of several insect species (for review, see Nässel, 1999). In arthropods, it was reported that histamine increases chloride conductance (Claiborne and Selverston, 1984; Hardie, 1989; McClintock and Ache, 1989; Gisselmann et al., 2002) and that its receptors are members of the ligand-gated chloride channel family.

Here, we identified novel genes involved in temperaturepreference regulation: histidine decarboxylase $(h d c)$ and two histamine receptors, ora transientless (ort) and histamine-gated chloride channel subunit 1 ( hisCl1). Drosophila strains with mutations in these genes showed abnormal temperature preferences. Furthermore, we found that these genes are essential in determin- 
ing critical thermal limits (insects enter a state of coma when they go beyond this temperature limit) (Shreve et al., 2004). Moreover, expression of these genes was detected in various regions of the brain, further supporting their critical roles. Collectively, these results implicate that the histaminergic system participates in regulating physiological responses to cold temperature (or thermal threshold to low and high temperature) as well as modulating temperature preference.

\section{Materials and Methods}

A device for assaying Drosophila temperature preferences. To assay preference for temperature of adult Drosophila, a temperature gradient from 15 to $45^{\circ} \mathrm{C}$ with a slope of $0.75^{\circ} \mathrm{C} / \mathrm{cm}$ was produced in an aluminum block (42 length $\times 24$ width $\times 7 \mathrm{~cm}$ height). Electronic thermal sensors were embedded in the block every $3 \mathrm{~cm}$, and the gradient was established using cold and hot circulating water chambers at each end. A glass plate with five separate lanes was placed $2.5 \mathrm{~mm}$ above the block, creating suitable spaces for flies to migrate. The glass plate was slightly coated with quinine sulfate powder, an aversive stimulus for Drosophila, to prevent flies from escaping the temperature gradient by resting on the walls or roof of the lane. Adult flies were placed between the aluminum block and the glass plate, allowed to migrate for $25 \mathrm{~min}$ in the dark, and photographed with a digital camera. All experiments were performed in a room where the temperature and humidity were kept constant at $25^{\circ} \mathrm{C}$ and $40-45 \%$, respectively. The age of all flies tested was synchronized at $4-5 \mathrm{~d}$. The number of flies counted was recorded and processed using Excel (Microsoft, Redmond, WA).

Fly stocks and genetics. All enhancer and promoter (EP)-elementinserted Drosophilia melanogaster mutants used for the large-scale genetic screen were provided by GenExel (Daejeon, Korea). GenExel generated 100,000 independent EP lines, mapped the EP insertion positions by inverse PCR and DNA sequencing, and selected proximately 27,000 EP lines based on EP-element insertion positions to remove redundant lines. All autosomal EP lines were derived from a single $w^{1118}$ background male fly with an EP insertion on the $\mathrm{X}$ chromosome, and all $\mathrm{X}$-chromosomal EP lines were also generated from a single male fly, but with an EP insertion on the second chromosome. The EP element was mobilized by crossing with a P-element transposase-source line (delta2-3 line). The delta2-3 line has all the chromosomes of the same $w^{1118}$ line used to produce the EP lines, except for the chromosome containing the transposase gene. Therefore, we believe that the EP lines used in the screen had minimal variation in genetic background.

The $h d c$ mutant allele $\left(h d c^{\mathrm{JK} 910}\right)$ and ort ${ }^{\mathrm{P} 306}$ were kindly provided by Dr. W. Pak (Purdue University, West Lafayette, IN). ort ${ }^{1}$ was obtained from the Bloomington Stock Center (Bloomington, IN). For behavioral assays, flies not older than $5 \mathrm{~d}$ were used. The ort ${ }^{\mathrm{P} 306}$ mutant has an eight-nucleotide deletion ( -276 to -269 , in which the proposed translation start site is +1 ) in the $5^{\prime}$ untranslated region of ort cDNA. This mutant has dramatically reduced ort mRNA levels (Gengs et al., 2002). The ort ${ }^{1}$ mutant has a deletion of 569 nucleotides overlapping intron 2 (110 bp) and 459 nucleotides of exons 2 and 3 . The deletions lead to the loss of the sequence encoding a substantial portion of the N-terminal extracellular domain and the first two membrane-spanning segments and also introduce a frameshift. Thus, ort ${ }^{1}$ flies are null mutants (Iovchev et al., 2002). All mutants were outcrossed with $w^{1118}$.

The $h d c^{\mathrm{JK} 910}$ was generated by Dr. J. Merriam (University of California at Los Angeles, Los Angeles, CA). $h d c^{\mathrm{JK} 910}$ showed very low levels (10-fold less than wild type) of histamine synthesis (Sarthy, 1991; Burg et al., 1993). To generate his Cl1 deletion mutants, we used the EP73547 line carrying a P-element located at the $5^{\prime}$ end of hisCl1 (33 bp upstream). EP73547 was a healthy and homo-viable line. Imprecisely excised lines generated by delta2-3 transposase (EP73547/TMS, delta2-3) (see Fig. $2 C$ ) were selected by screening for loss of eye color. Genomic DNA was extracted using G-spin (iNtRON, Daejeon, Korea) from adult flies. The extent of deletions was determined by PCR analysis of mutant genomic DNA using primers based on the Drosophila genome sequence. The forward and reverse primers were as follows: $5^{\prime}$-ATTGTAGAGCACGTATTTGC-3' and $5^{\prime}$-TCCATCATAGGAACGTTGTC- $3^{\prime}$. Each reaction $(20 \mu \mathrm{l})$ contained 50
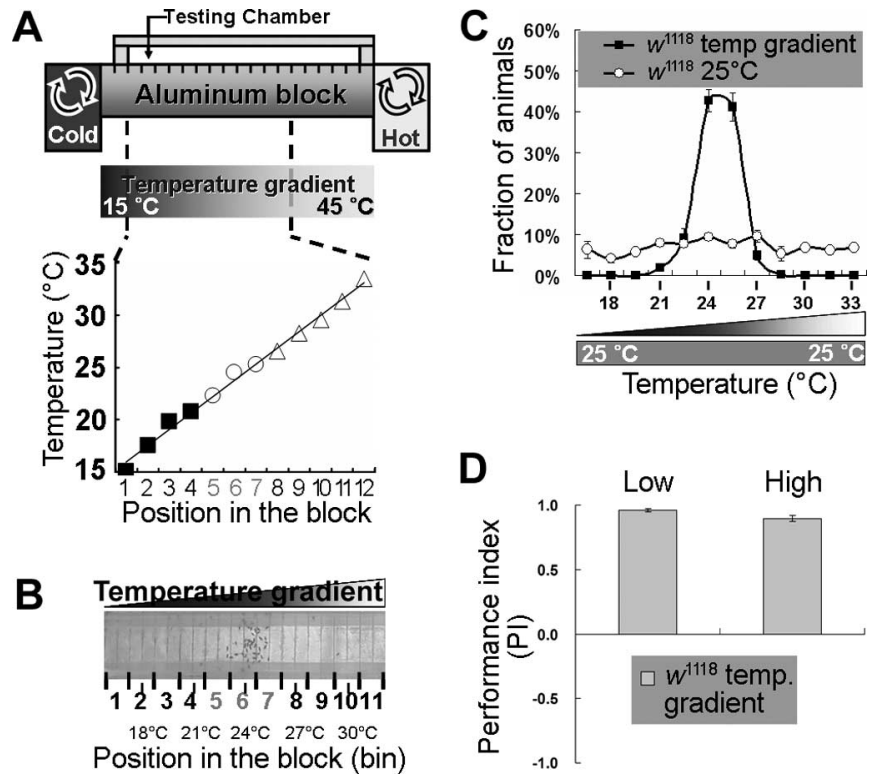

Figure 1. Measurement of the temperature preference in Drosophila. $A$, Temperature from 15 to $45^{\circ} \mathrm{C}$ in a linear gradient. A temperature gradient was established by transmission along the long axis of aluminum block. The temperature of cold water was $4^{\circ} \mathrm{C}$, and the temperature of hot water was $50^{\circ} \mathrm{C} . \boldsymbol{B}, \boldsymbol{C}$, Control flies $\left(\mathrm{w}^{1118}\right)$ aggregated th the region of intermediate temperature $\left(22-25^{\circ} \mathrm{C}\right.$; gray numbers in $\left.\boldsymbol{B}\right)$ when a stable temperature gradient was established. Flies were distributed evenly when $24-25^{\circ} \mathrm{C}$ was sustained across the block ( $\boldsymbol{C}$, open circle). The vertical axis represents the percentage of flies populated in each temperature bin. $\boldsymbol{D}$, The PI for the control flies. Control flies exhibited no preference to low $\left(15-21^{\circ} \mathrm{C}\right)$ and high $\left(27-33^{\circ} \mathrm{C}\right)$ temperature. Error bars denote SEM. PI values: 1 , all flies resided in the $22-25^{\circ} \mathrm{C}$ region and none resided in the low or high temperature region; 0 , all flies distributed evenly between the intermediate and low (or high)-temperature region; -1 , all flies in the low- or high-temperature region. temp, Temperature.

mм KCl, $1.5 \mathrm{~mm} \mathrm{MgCl}_{2}, 0.2 \mathrm{~mm}$ dNTP, $0.5 \mu \mathrm{m}$ of each primer, $2.5 \mathrm{U}$ of Taq polymerase (Bioneer, Daejeon, Korea), and $20 \mathrm{~mm}$ Tris- $\mathrm{HCl}, \mathrm{pH}$ 8.4. The reaction mixture was denatured initially for $5 \mathrm{~min}$ at $94^{\circ} \mathrm{C}$ and subjected to 35 cycles of $94^{\circ} \mathrm{C}$ for $40 \mathrm{~s}, 55^{\circ} \mathrm{C}$ for $90 \mathrm{~s}$, and $72^{\circ} \mathrm{C}$ for $2 \mathrm{~min}$, with a final $72^{\circ} \mathrm{C}$ extension for $10 \mathrm{~min}$. Approximately 500 excision lines were screened, yielding seven deletions, two of which, his $\mathrm{Cll}^{134}$ (1.7 kb deletion) and his $\mathrm{Cll}^{384}$ (1.0 $\mathrm{kb}$ deletion), were used for additional studies. To address whether hisCl1 mRNA was transcribed from these two mutants, reverse transcription (RT)PCR was performed as described below.

To generate a double mutant for the histamine-gated chloride channels, $o r t^{1}$ and $h i s C l 1^{134}$ mutants were crossed. Recombined double mutants were balanced with the third chromosome balancer, TM6b. To confirm the double mutation, PCR was performed with the following primers: for his Cll, 5'-ATTGTAGAGCACGTATTTGC-3' and 5' -TCCATCATAGGAACGTTGTC-3'; for ort, $5^{\prime}$-CAAAGTCTGGCCATAACCGAC-3' and $5^{\prime}$ AACAGGTGGCAAAGACGACTG-3' . All null mutants of the histaminesignaling genes showed normal external morphologies and seemed healthy.

All flies were grown at $24-25^{\circ} \mathrm{C}$ in a $12 \mathrm{~h}$ light/dark cycle on standard medium. Strain $w^{1118}$ was used as the wild-type control.

Behavioral analysis and large-scale genetic screen for temperature preference. As described previously (Lee et al., 2005), we performed a temperature-preference behavior screen on $>27,000$ independent EPelement insertion mutant lines. We tested each line at least twice with $\sim 100$ flies of mixed sexes per trial. Newly eclosed adult flies $<1-2 \mathrm{~d}$ of age were collected in vials containing fresh food during morning hours. They were not anesthetized. After $4 \mathrm{~d}$ under a $12 \mathrm{~h}$ light/dark incubation cycle, the collected flies were placed in the test device described above. $w^{1118}$ was used as a wild-type control because all of the EP lines tested were generated in the genetic background of $w^{1118}$ by GenExel or histamine treatment; 4 -d-old $h d c^{\mathrm{JK} 910}$ adult flies were transferred to a vial containing a Whatman (Clifton, NJ) filter disc soaked in either distilled water with $10 \%$ sucrose (control) or $5 \%$ aqueous histamine diphosphate 
A

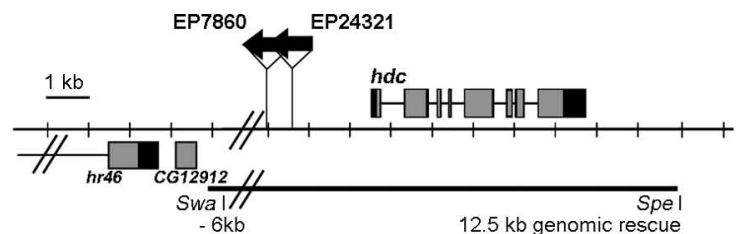

B

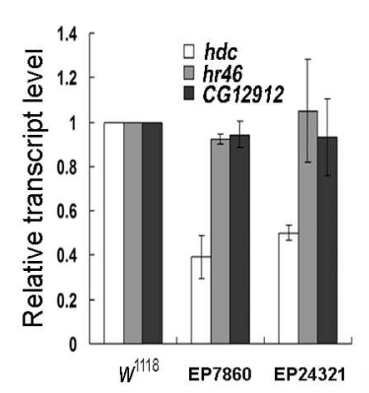

C
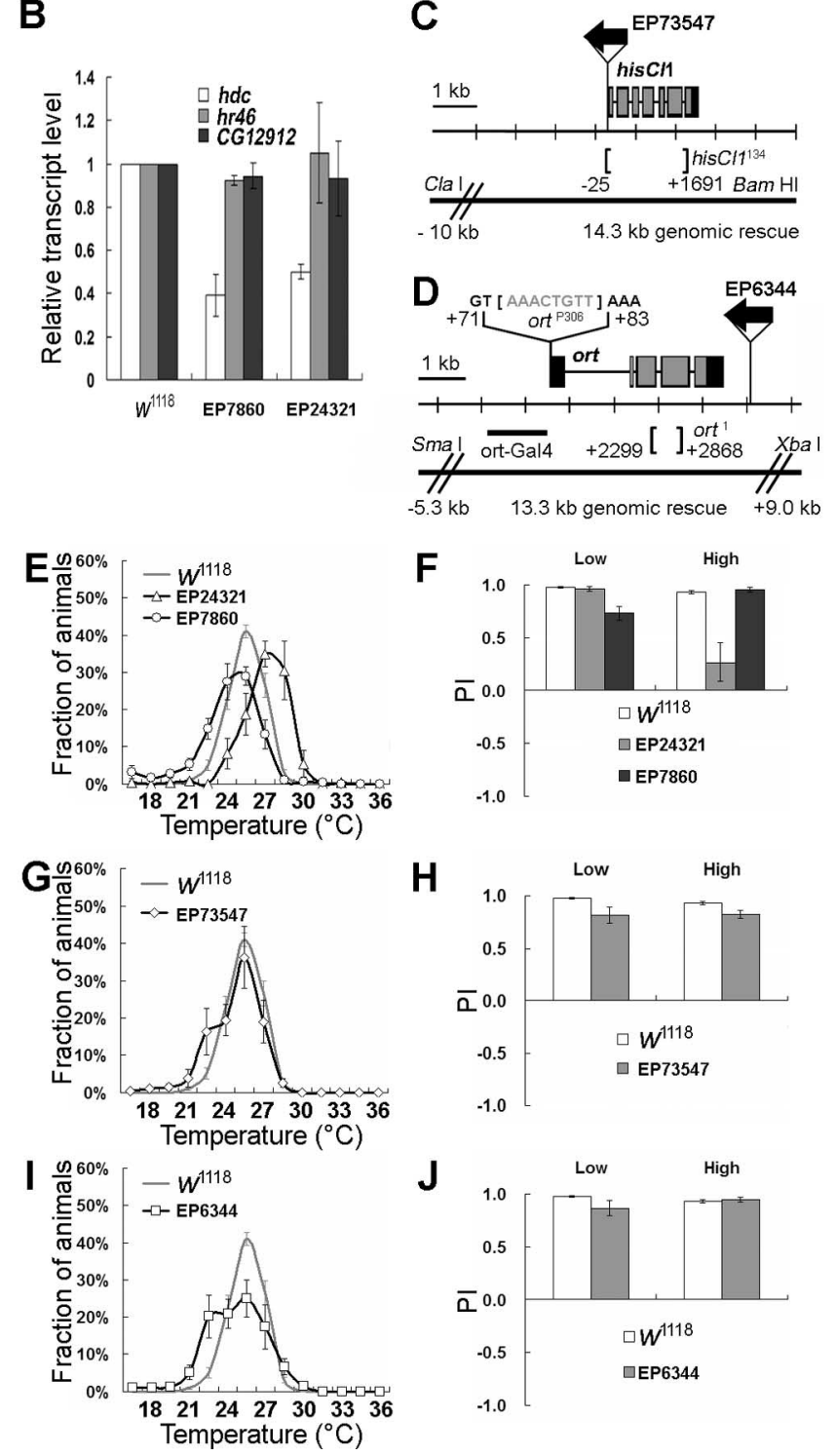

H

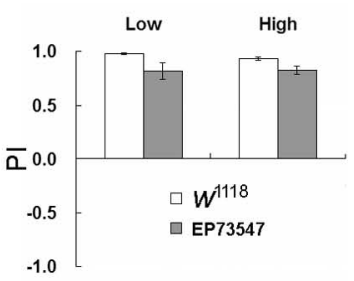

J

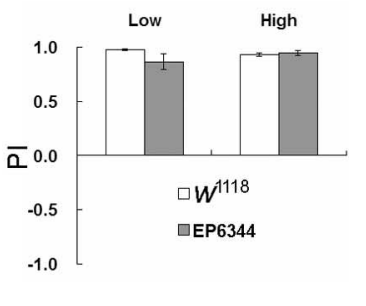

Figure 2. EP lines with abnormal temperature preferences. $\boldsymbol{A}, \mathrm{EP}$ lines with insertions nearby histidine decarboxylase ( $h d c)$. Both EP24321 and EP7860 contained a P element at $\sim 2$ $\mathrm{kb}$ upstream from the $5^{\prime}$ end of $h d c$. The genomic fragment regions, used for genomic rescue, are depicted as a long, thick black line under the scale bar in $\boldsymbol{A}, \boldsymbol{C}$, and $\boldsymbol{D}$. $\boldsymbol{B}$, Real-time RT-PCR results showing relative fold changes of $h d c, h r 46$, and (G12912 transcript levels in EP24321 and EP7860. Only hdc transcript levels were reduced in both EP lines compared with wild-type control. Three independent experiments were performed in triplicate. C, The EP73547 line has a $P$ element located at 33 bp upstream from the $5^{\prime}$ end of the his $C 11$ gene. Homozygotes for EP73547 were fertile and healthy. his $C 1{ }^{134}$ is a null mutant with deletion of $1.7 \mathrm{~kb}$ depicted as square brackets. D, EP6344 has a P element at 1244 bp downstream from the $3^{\prime}$ end of the ort gene. The ort-Gal 4 construct contains a genomic fragment of $1357 \mathrm{bp}$ (short black line). ort ${ }^{\mathrm{P} 06}$, a hypomorphic allele, has an 8 bp deletion in the $5^{\prime}$ untranslated region. ort ${ }^{1}$ is a null allele without 569 bp of the ort gene. $\boldsymbol{E}, \boldsymbol{F}$, Temperature-preference profiles $(\boldsymbol{E})$ and PI values $(\boldsymbol{F})$ for EP7860 and EP24321. EP7860 and EP24321 showed abnormal temperature-preference profiles and PI values. EP24321 showed a thermophilic phenotype ( $p<0.05$, ANOVA; $\mathrm{PI}_{\text {High }}=0.27 \pm$ $0.19, p<0.001$, $t$ test), and EP7860 showed a cryophilic phenotype $\left(p<0.01, \mathrm{ANOVA} ; \mathrm{PI}_{\text {Low }}\right.$ $=0.73 \pm 0.06, p<0.001, t$ test). $\boldsymbol{G}, \boldsymbol{H}$, Temperature-preference profile $(\boldsymbol{G})$ and $\mathrm{PI}$ values $(\boldsymbol{H})$ for EP73547. PI $\mathrm{L}_{\text {Low }}$ of EP73547 is $0.82 \pm 0.08\left(p<0.01 ; t\right.$ test), and $\mathrm{PI}_{\text {High }}$ is $0.83 \pm 0.04$
(Sigma, St. Louis, MO) in 10\% sucrose and incubated overnight before the behavioral experiments. For hydroxyzine treatment, 4-d-old $w^{1118}$ adult flies were placed on agarose-containing vials supplemented only with $0.2 \mathrm{ml}$ of yeast paste (with the consistency of smooth peanut butter) made by thoroughly mixing $2.85 \mathrm{ml}$ of aqueous hydroxyzine $(20 \mathrm{mg} / \mathrm{ml}$, $2 \mathrm{mg} / \mathrm{ml}$; Sigma), $2.24 \mathrm{~g}$ of yeast (Baker's yeast), and $0.5 \mathrm{~g}$ of sucrose. For cimetidine treatment, 4 -d-old $w^{1118}$ adult flies were collected into vials, similar to those described above, except the supplement contained a paste made by thoroughly mixing $2.85 \mathrm{ml}$ of water, $2.24 \mathrm{~g}$ of yeast, $0.5 \mathrm{~g}$ of sucrose, and cimetidine powder $(0.4,25$, and $500 \mathrm{mg} / \mathrm{ml}$; Sigma). Control experiments were performed using the vials containing yeast paste without the drugs. After $24 \mathrm{~h}$ at $25^{\circ} \mathrm{C}$, feeding adult flies were harvested and analyzed. The performance index (PI) (Liu et al., 2003; Gray et al., 2004) of $22-25^{\circ} \mathrm{C}$ (intermediate temperature) versus $\mathrm{T}^{\circ} \mathrm{C}$ was calculated as follows: $\mathrm{PI}_{[\mathrm{T}]}=\left(N_{22-25}-N_{\mathrm{T}}\right) /\left(N_{22-25}+N_{\mathrm{T}}\right)$, where $N$ is the number of adult flies at a specified temperature.

Other behavioral assays. Flies were raised on standard medium at $25^{\circ} \mathrm{C}$ in a $12 \mathrm{~h}$ light/dark cycle and aged for 5-7 d after eclosion. Flies anesthetized with $\mathrm{CO}_{2}$ were placed in food-containing vials for $24 \mathrm{~h}$ before the assays to ensure full recovery from the effects of $\mathrm{CO}_{2}$. Behavioral assays were performed as follows. (1) Flight analysis was performed by dumping 20 males into the top of a cylinder of $800 \mathrm{~mm}$ height and $90 \mathrm{~mm}$ diameter with a plate of water at the bottom. The percentage of flies that did not fall immediately into the water was recorded as the flight index for that pool. (2) To measure resistance of young flies ( $5 \mathrm{~d}$ old $)$ to cold stress, flies were placed $(n=10)$ in a vial with food and kept at $4^{\circ} \mathrm{C}$, except for a $1 \mathrm{~h}$ recovery period $\left(25^{\circ} \mathrm{C}\right)$ daily before scoring mortality. (3) To test chillcoma recovery, flies $(n=10)$ were placed for $24 \mathrm{~h}$ in empty vials with a cotton plug on ice $\left(0-2^{\circ} \mathrm{C}\right)$. Flies were returned to room temperature and allowed to recover for $4 \mathrm{~h}$ (Macdonald et al., 2004). The number of aroused flies was counted immediately and at $5 \mathrm{~min}$ intervals. For exposure to histamine, 3- to 5-d-old adult flies were place for $24 \mathrm{~h}$ on histamine-containing vials made by thoroughly mixing histamine diphosphate (Sigma), 2\% heat-killed yeast (Baker's yeast), 5\% sucrose, and $1 \%$ agarose. (4) For knock-down analysis at $40^{\circ} \mathrm{C}$, flies were placed on an aluminum block of fixed temperature $\left(40^{\circ} \mathrm{C}\right)$, and the number of unconscious flies was recorded using digital photographs taken at $30 \mathrm{~s}$ intervals. (5) To measure arousal time after heat shock, vials containing the flies were put into a water bath fixed at $41^{\circ} \mathrm{C}$ for $10 \mathrm{~min}$. All flies were knocked-down within $10 \mathrm{~min}$. After that, the vials were removed from the bath and placed on a shelf at room temperature. The number of aroused flies was counted immediately and at $2 \mathrm{~min}$ intervals.

Genetic rescue of $\mathrm{hdc}^{\mathrm{JK} 910}$, ort ${ }^{1}$, and hisCl1 ${ }^{134}$. To make an $h d c$ (CG3454) genomic rescue construct, an SwaI/SpeI-digested genomic fragment of $12.5 \mathrm{~kb}$, bearing sequences $\sim 6 \mathrm{~kb}$ upstream from the transcription start site and $2 \mathrm{~kb}$ downstream from the transcription stop site, was cloned into pCasper vector. To make an hisCl1 (CG14723) genomic rescue construct, a ClaI/Bam $\mathrm{HI}$-digested genomic fragment of $14.3 \mathrm{~kb}$ including sequences $\sim 10 \mathrm{~kb}$ upstream and $2 \mathrm{~kb}$ downstream was cloned in pCasper vector. To make an ort (CG7411) genomic rescue construct, an EagI/XbaI-digested genomic fragment of $13.3 \mathrm{~kb}$ including sequences $\sim 5.3 \mathrm{~kb}$ upstream and $5 \mathrm{~kb}$ downstream was cloned in pCasper vector. Each genomic rescue construct for $h d c$, ort, and hisCll was injected into embryos of $h d c^{\mathrm{JK} 910}$, ort ${ }^{1}$, and $h i s C l 1^{134}$ mutants, respectively. DKO-res, a rescued DKO mutant, was generated by crossing DKO mutants having his $\mathrm{Cl} 1$ genomic rescue constructs with DKO mutants having ort genomic rescue constructs.

To construct UAS-ort, $\sim 3 \mathrm{~kb}$ of an ort cDNA (kindly provided by Dr. Pak) fragment was cloned into pUAST. An ort-Gal4 construct was generated using pPTGAL vector (Sharma et al., 2002) and 1357 bp of sequence upstream from the transcription start site of the ort gene

In situ hybridization and immunohistochemistry. In situ hybridization

$\leftarrow$

$(p<0.01 ; t$ test). PI values are significantly different from control. EP73547 showed abnormal temperature behavior. $\boldsymbol{I}, \boldsymbol{J}$, Temperature-preference profile $(\boldsymbol{I})$ and PI values $(\boldsymbol{J})$ for EP6344. $\mathrm{PI}_{\text {Low }}$ of EP6344 is $0.87 \pm 0.07(p<0.05 ; t$ test $)$, and $\mathrm{PI}_{\text {High }}$ is $0.95 \pm 0.02$ ( $p>0.05$; t test). EP6344 showed a weak tendency to the low-temperature region. Error bars denote SEM. 

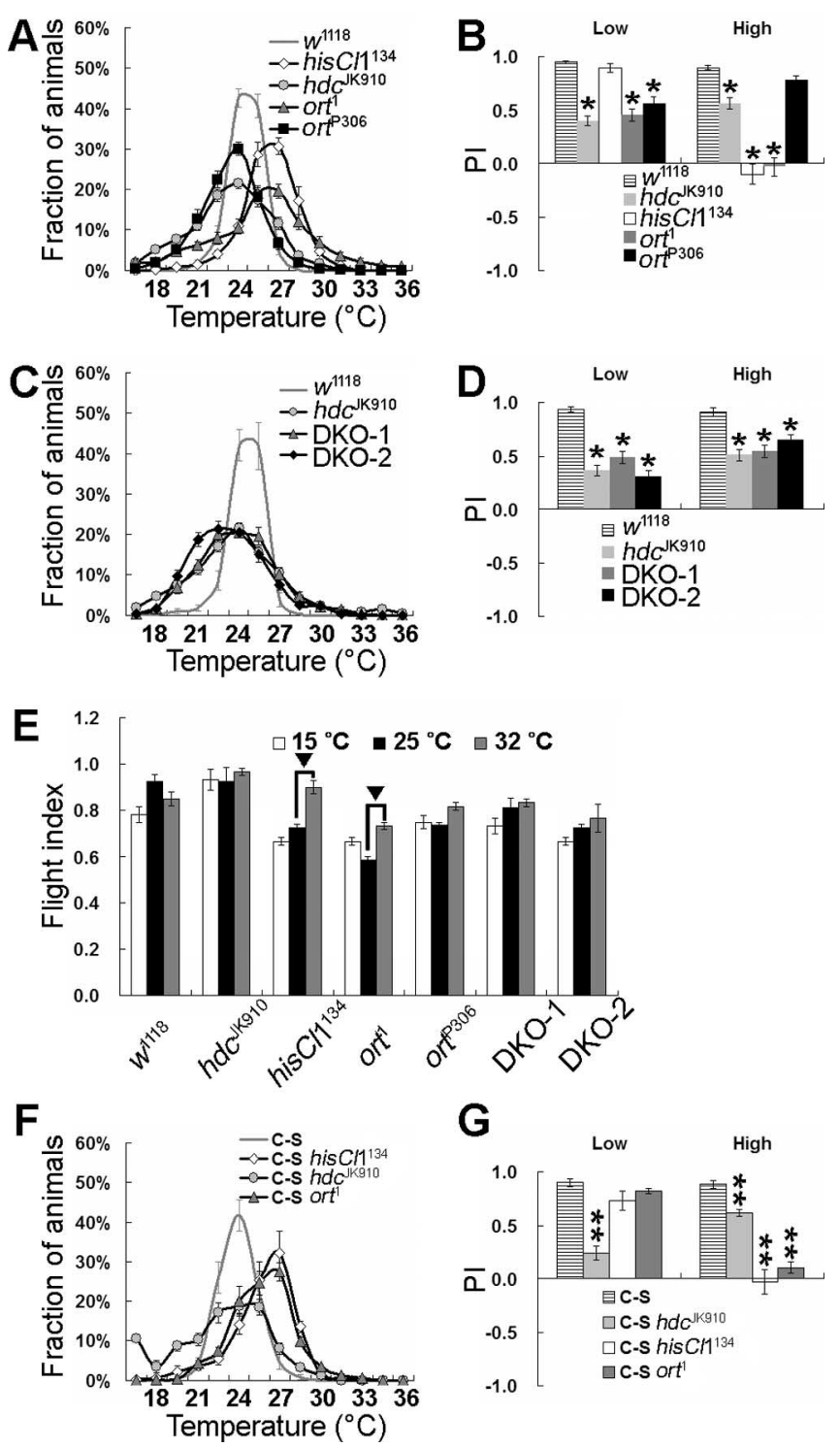

Figure 3. Defects in the histaminergic system cause abnormal temperature preferences. $w^{1118}$ was used as a wild-type control. $\boldsymbol{A}, \boldsymbol{B}$, The mutants for the histaminergic system showed abnormal temperature preferences. $h d c^{\mathrm{JK} 910}$ is a null mutant of histidine decarboxylase. In $h d c^{\mathrm{JK} 910}, \mathrm{Pl}$ indices to low and high temperature were lowered to $\sim 40$ and $56 \%$, respectively, compared with wild-type. The hisCl1 null mutant his $C / 1{ }^{134}$ showed significantly reduced avoidance to high temperature or thermophilic behavior. Hypomorph ort ${ }^{\mathrm{P} 306}$ showed that the PI to low temperature was lowered but the PI to high temperature was not significantly different from wild type. The ort ${ }^{1}$ null mutant showed an increased preference for hot temperature compared with ort ${ }^{\mathrm{P} 306} .{ }^{*} p<0.001$ versus $w^{1118}$ ( $t$ test). C, D, Histamine receptor DKO mutants DKO-1 and $-2\left(\mathrm{w}_{;} ;\right.$his $C / 1^{134}{ }^{13}$ ort $\left.{ }^{1}\right)$ and $h d c^{\mathrm{JK} 910}$ mutant showed very similar behavioral patterns (the significance for $h d c^{\mathrm{JK}}{ }^{1010}$ and DKOs, $p=0.6090$ and $p=0.1304$, respectively; ANOVA). $\boldsymbol{E}$, Abnormal temperature preferences in the histaminergic mutants were not from the defects in motor activity. The histaminergic mutants showed normal motor activity in three representative temperature conditions $\left(15,25\right.$, and $\left.32^{\circ} \mathrm{C}\right)$ on the flight-assay paradigm. $\nabla, p<0.01$ versus $w^{1118}$ ( $t$ test). $\boldsymbol{F}, \mathbf{G}$, Effects of outcrossing on temperature preference. Cantonized histaminergic mutants displayed similar preferences for temperature compared with the corresponding mutants in the $w^{1118}$ background. ${ }^{* *} p<0.001$ versus $C-S$ ( $t$ test). Error bars indicate SEM.

(ISH) was performed as described previously (O’Neill and Bier, 1994). Adult brains were dissected in PBS and fixed in PBS with $4 \%$ formaldehyde at room temperature for $30 \mathrm{~min}$. In vitro transcription was performed using $250 \mathrm{ng}$ of PCR-amplified DNA template and the digoxigenin (DIG) or fluorescein RNA labeling mix (Roche, Stockholm, Sweden). DIG or fluorescein-labeled RNA sense and antisense probes were transcribed by T7 RNA polymerase for $2 \mathrm{~h}$. The T7 promoter sequence was inserted directly at the end of a template. The probes were stored until use in hybridization solution (50\% formamide, $5 \times$ SSC, $0.1 \mathrm{mg} / \mathrm{ml}$ heparin, $0.1 \mathrm{mg} / \mathrm{ml}$ salmon sperm DNA, and $0.1 \%$ Tween 20 ) at $-20^{\circ} \mathrm{C}$. After prehybridization for a minimum of $2 \mathrm{~h}$ in hybridization solution at $55^{\circ} \mathrm{C}$, the tissues were incubated with probes overnight at $55^{\circ} \mathrm{C}$. The ort probe corresponds to nucleotides 421-1475.

The hybridized RNA signals were visualized using sheep anti-DIG or fluorescein-HRP (Fab fragment; Roche) and fluorescent tyramides (NEN Life Sciences, Boston, MA) or sheep anti-DIG-alkaline phosphatase (Fab fragment; Roche) and nitroblue tetrazolium/5-bromo-4chloro-3-indolyl phosphate stock solution (Roche). Tissues were mounted in a glycerol-based mountant and examined by confocal microscopy (LSM510; Zeiss, Thornwood, NY).

Ort and HisCl1 antisera were obtained from rats immunized with glutathione $S$-transferase fusion proteins corresponding to nucleotide 1348-1716 of ort cDNA and nucleotide 1194-1333 of hisCl1, respectively (Peptron, Daejeon, Korea). For ORT and His Cll antibody staining, tissues were fixed in a fresh solution of $4 \%$ paraformaldehyde dissolved in PBS containing $0.5 \%$ Triton X-100, pH 7.2. Antibody incubations were performed with $5 \%$ normal goat serum, and dilutions were 1:1000 for rat anti-Ort, 1:500 for rat anti-HisCl1, 1:300 for goat anti-rat Rhodamine Red X (Jackson ImmunoResearch, West Grove, PA), and 1:300 for donkey anti-rat FITC (Jackson ImmunoResearch). For histamine antibody staining, tissues were fixed in a fresh solution of 4\% 1-ethyl-3-(3dimethylaminopropyl) carbodiimide hydrochloride (Sigma) dissolved in PBS containing $0.2 \%$ Triton X-100, pH 7.2 (PBST). After rinsing in PBST, they were treated in blocking solution (BS) containing $3 \%$ normal goat serum (in PBST). Tissues were then incubated overnight in the histamine antibody (1:500 in BS; Diasorin, Stillwater, MN). Washes in PBST were followed by incubation of the secondary antibody (1:250 goat anti-rabbit tetramethylrhodamine isothiocyanate in BS; Jackson ImmunoResearch). After final rinsing in PBST, samples were mounted in a glycerol-based medium (Python and Stocker, 2002).

Specificity of ISH and immunohistochemistry was verified by hybridization with sense probes (performed under identical conditions) and by using a null mutant background or UAS/GAL4 (data not shown).

Real-time PCR and RT-PCR. Total RNA was extracted using the Absolutely RNA miniprep kit (Stratagene, La Jolla, CA) and reverse transcribed using AMV reverse transcriptase (Promega, Madison, WI). RT-PCR was performed with the following primers: for hisCl1, 5'-TCAAAGCCGAAGGTAGTGTG $-3^{\prime}$ and 5' - ACCGTGACATGGAAGTAGAC-3'; for ort, 5' -CTGCAAATGGAAAGCCTGTC- $3^{\prime}$ and $5^{\prime}$-TCAACGTTTAACACTCGGATG-3'; for rp 49, $5^{\prime}$-ATGACCATCCGCCCAGCATAC- $3^{\prime}$ and $5^{\prime}$-GAGAACGCAGGCGACCGTTGG$3^{\prime}$. The reaction mixture was denatured initially for $5 \mathrm{~min}$ at $94^{\circ} \mathrm{C}$ and subjected to 35 cycles of $94^{\circ} \mathrm{C}$ for $45 \mathrm{~s}, 55^{\circ} \mathrm{C}$ for $45 \mathrm{~s}$, and $72^{\circ} \mathrm{C}$ for $1 \mathrm{~min}$, with a final $72^{\circ} \mathrm{C}$ extension for $10 \mathrm{~min}$.

Real-time PCR was performed using the Greenstar PCR master mix (Bioneer) on an iCycler iQ (Bio-Rad, Hercules, CA). rp49 levels were measured and used as an internal control for the RNA amount in each sample. The primer sets were as follows: for $h d c, 5^{\prime}$-TCGGATAGCGCACCAGGAATC- $3^{\prime}$ and $5^{\prime}$-CTGGTACGAGTGGCTCCATTG- ${ }^{\prime}$; for

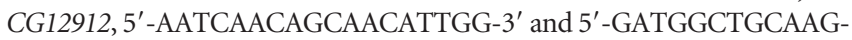
GCTGCGCTG-3'; for $h r 46,5^{\prime}$-GCATTACGGAGTGATCACCTG-3' and $5^{\prime}$-TGCCGAACTTTACAGCATCAC-3'; for $r p 49$, 5' $5^{\prime}$-ATGACCATCCGCCCAGCATAC-3' and 5'-CTTGCGCCATTTGTGCGACAG-3'. Results are expressed as fold change relative to an arbitrary calibrator sample, thereby allowing qualitative comparison of a single mRNA species between different samples, although the relative expression levels of different mRNA species cannot be assessed by this method.

\section{Results}

Measurement of the temperature preference of Drosophila

The temperature preference of adult Drosophila was examined on a linear temperature gradient. A temperature gradient from 15 to $45^{\circ} \mathrm{C}$ was maintained in a $42 \mathrm{~cm}$ aluminum block (Fig. $1 \mathrm{~A}$ ). For testing, $\sim 45-70$ flies were transferred from a culture vial to each lane of the gradient through holes in the cover.

Consistent with the previous findings, wild-type flies showed 

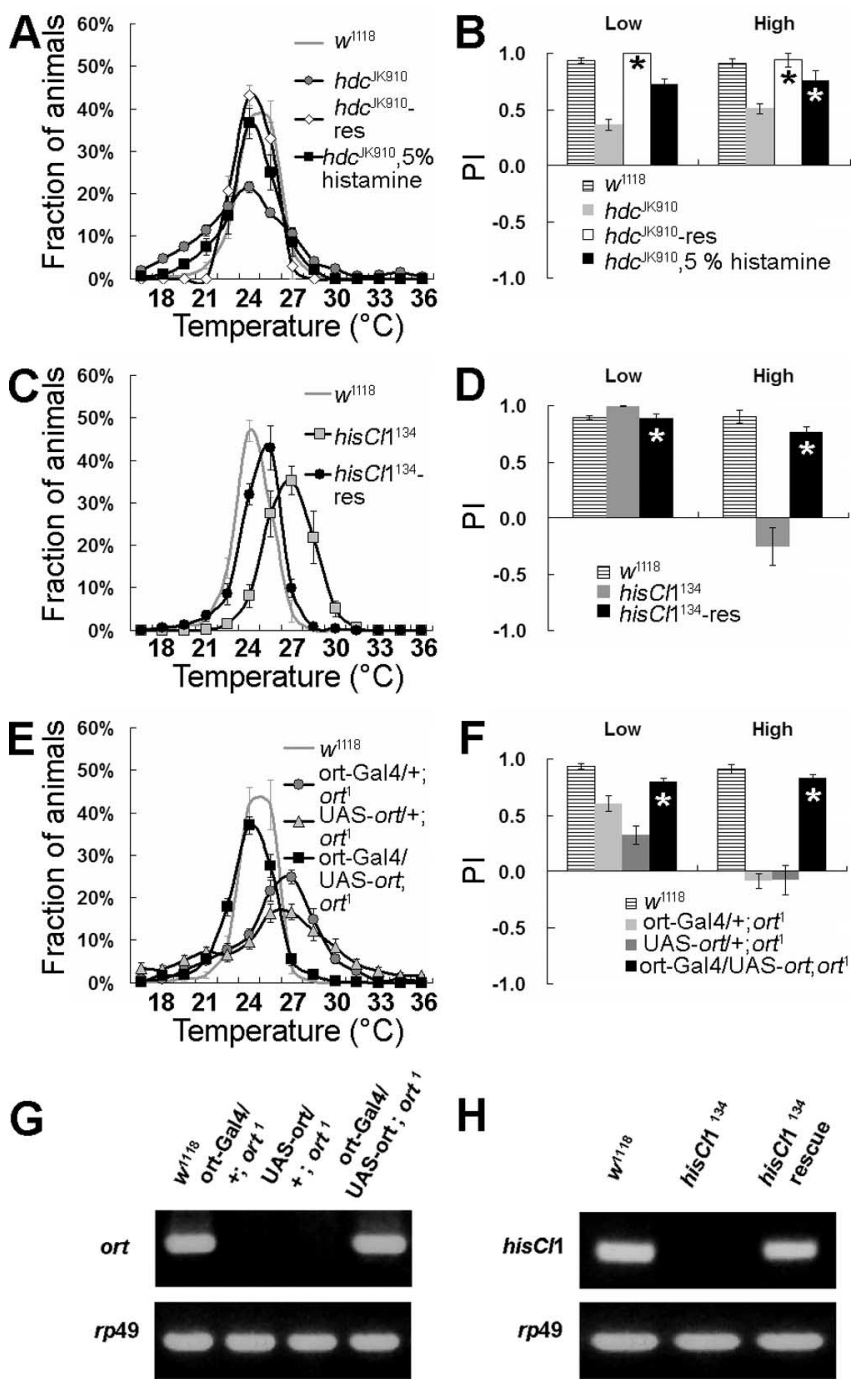

Figure 4. Altered temperature preferences in the histaminergic mutants are rescued by genetic and pharmacological experiments. $\boldsymbol{A}, \boldsymbol{B}$, The abnormal temperature preference of $h d c^{\mathrm{JK} 910}$ was restored by expression of the $h d c$ genomic transgene ( $h d c^{\mathrm{JK} 910}$-res). $\boldsymbol{B}, \mathrm{PI}$ values showed that $h d{ }^{\mathrm{J}}{ }^{\mathrm{9} 910}$ mutants were significantly rescued. By histamine administration, $h d-$ $C^{\mathrm{Jk}}{ }^{1010}$ was also significantly rescued. $\boldsymbol{C}, \boldsymbol{D}$, The thermophilic behavior of the his $\mathrm{C} / 1$ null mutant was rescued by the $h i s\left(1 /\right.$ genomic transgene (his $/ 11^{134}$-res). $\boldsymbol{E}, \boldsymbol{F}$, The UAS-ort transgene in the ort ${ }^{1}$ null background restored the ort ${ }^{1}$ phenotype, when driven under the control of ort-Gal4. G, RT-PCR confirmed that the ort-Gal4-driven UAS-ort transgene was effectively expressed in the ort ${ }^{1}$ null mutant background. $r p 49$ was used as an internal control. $\boldsymbol{H}, \mathrm{RT}$-PCR showed that his $/ 11^{134}$-rescue containing $14.3 \mathrm{~kb}$ of the his $/ 11$ genomic fragment expressed $h$ is $\mathrm{Cl}$ transcripts properly. Error bars indicate SEM. Asterisks denote no significant difference compared with $w^{1118}$ control ( $t$ test).

a strong temperature preference at $24-25^{\circ} \mathrm{C}$ (Fig. $1 B, C$ ) (Sayeed and Benzer, 1996; Zars, 2001), and the average preference temperature for the population was $24.4-24.6^{\circ} \mathrm{C}$. To quantify adult behavior on a temperature gradient using a PI (Liu et al., 2003; Rosenzweig et al., 2005), we compared and calculated numerically the distribution of animals between intermediate temperature (bins 5-7) and high (bins 8-14) or low (bins 1-4) temperature (Fig. $1 B, D$ ). For example, $\mathrm{PI}_{[\text {Low }]}=1$ means that all flies resided in the $22-25^{\circ} \mathrm{C}$ region and none resided in the $15-21^{\circ} \mathrm{C}$ region (low temperature). $\mathrm{PI}_{[\mathrm{Low}]}=0$ means that all flies distributed evenly in both regions. $\mathrm{PI}_{[\mathrm{Low}]}=-1$ means all flies were in the $15-21^{\circ} \mathrm{C}$ region. $\mathrm{PI}_{[\mathrm{High}]}$ indicates a $\mathrm{PI}$ for the $27-33^{\circ} \mathrm{C}$ region. Wild-type animals exhibited no preference in the absence of a temperature gradient (fixed at $24-25^{\circ} \mathrm{C}$ (Fig. $1 \mathrm{C}$, open circle).
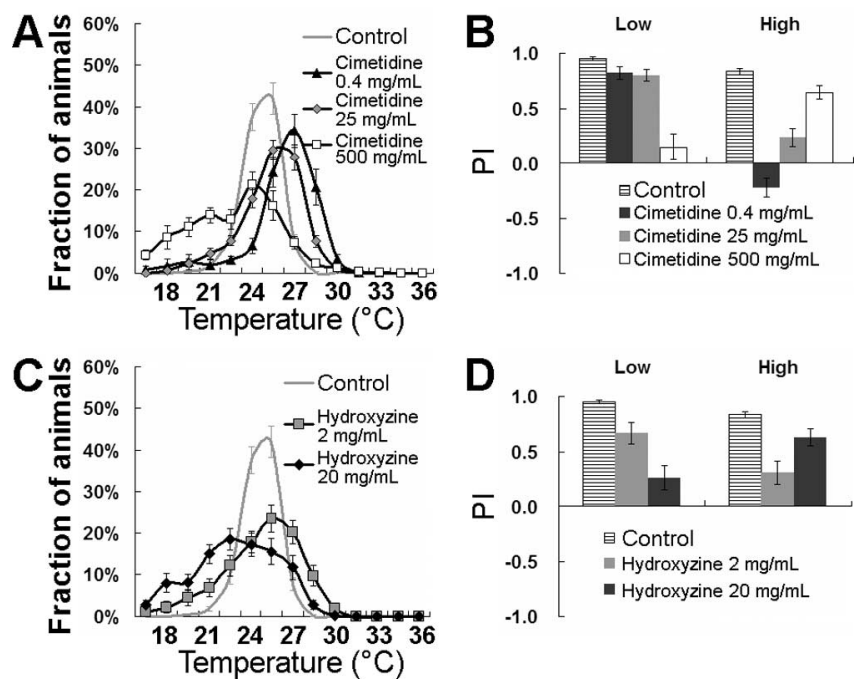

Figure 5. Histamine receptor antagonists, hydroxyzine and cimetidine, cause the altered temperature preference shown in the $h d c^{\mathrm{J}}{ }^{\mathrm{K} 910}$ mutant. $\boldsymbol{A}, \boldsymbol{B}$, Cimetidine $(500 \mathrm{mg} / \mathrm{ml})$ induced flies to behave like $h d c^{J K 910}$. The significance for $h d c^{\mathrm{J}}{ }^{\mathrm{J}} 10$ and the $500 \mathrm{mg} / \mathrm{ml}$ cimetidinetreated fly was $p=0.1232$ (ANOVA). C, D, Behavior patterns caused by a dose of $20 \mathrm{mg} / \mathrm{ml}$ hydroxyzine are similar to $h d c^{\mathrm{JK} 910}$. At low doses $(2 \mathrm{mg} / \mathrm{ml})$, flies behave like the $h i s\left(11^{134}\right.$ null mutant or the ort ${ }^{1}$ null mutant. Hydroxyzine $(20 \mathrm{mg} / \mathrm{ml})$-treated flies showed an altered temperature preference profile pattern ( $p=0.0001$; ANOVA) but was statistically not the same as that of $h d c^{\mathrm{JK} 910}$ (the significance for $h d c^{\mathrm{J}}{ }^{\mathrm{K} 910}$ and $20 \mathrm{mg} / \mathrm{ml}$ hydroxyzine; $p<0.0001$, ANOVA). Error bars indicate SEM.

EP lines linked to the genes of the histaminergic system show abnormal temperature preferences

From a large-scale temperature-preference behavior screen on $>27,000$ independent EP mutant lines, described in Materials and Methods, we selected 457 lines showing abnormal temperature preferences. From these, we found a mutant line, EP24321, that showed a thermophilic (high-temperature-loving) phenotype $\left(p<0.05\right.$, ANOVA; $\mathrm{PI}_{\mathrm{High}}=0.27 \pm 0.19, p=0.0002, t$ test $)$. This mutant contains a $\mathrm{P}$ element at $\sim 2 \mathrm{~kb}$ upstream of the histidine decarboxylase gene $h d c$ (Fig. $2 A, E, F$ ).

To evaluate the effect of EP24321 on temperature preference, another P-insertion line, EP7860, which also contains a P element nearby $h d c$, was subjected to the temperature-preference assay. EP7860 also showed an abnormal temperature-preference profile compared with control (Fig. $2 E)(p<0.01$; ANOVA) and a cryophilic phenotype (Fig. $2 F)\left(p<0.001\right.$ vs $w^{1118} ; t$ test). Both EP24321 and EP7860 contain a P element at $\sim 2 \mathrm{~kb}$ upstream from the $5^{\prime}$ end of the $h d c$ gene. To assess whether the abnormal phenotypes result from deficits of $h d c$ expression, we compared the level of $h d c$ mRNA from EP7860, EP24321, and $w^{1118}$ wildtype flies using real-time PCR. Three independent experiments with separate RNA preparations from head samples revealed that $h d c$ transcript levels in EP7860 and EP24321 were $61 \pm 10 \%$ and $50 \pm 3 \%$ lower, respectively, than that in wild-type flies (Fig. 2 B).

Because the locations of the P element in both EP24321 and EP7860 were relatively far from the $h d c$ transcription start site, it was possible that a disruption in other nearby genes resulted in the abnormal thermal behaviors. To rule out this possibility, we examined whether each EP line had influence on the transcription level of nearby genes. CG12912 and $h r 46$, located at $\sim 4 \mathrm{~kb}$ upstream from EP7860 and EP24321, are the genes closest to the sites of insertion of both P elements (Fig. 2A). As shown in Figure $2 B$, real-time PCR analysis revealed that transcript levels of CG12912 and $h r 46$ were not affected by the P-element insertion in EP7860 or EP24321. Therefore, we concluded that the abnor- 
Table 1. Statistical analyses of the variance for the temperature preferences

\begin{tabular}{|c|c|c|c|c|c|c|}
\hline \multirow[b]{2}{*}{ Genotype } & \multirow[b]{2}{*}{$N(n)$} & \multirow{2}{*}{$\begin{array}{l}\text { Average temperature } \\
\left({ }^{\circ} \mathrm{C}\right) \pm S D\end{array}$} & \multicolumn{2}{|c|}{ Comparing within replicates } & \multicolumn{2}{|c|}{ Comparing with $w^{1118}$ control } \\
\hline & & & Fvalue & $p$ value & Fvalue & $p$ value \\
\hline$w^{1118}$ & $17(1009)$ & $24.4 \pm 1.1$ & 0.40 & 0.98 & & \\
\hline EP24321 & $9(445)$ & $26.7 \pm 1.4$ & 1.55 & 0.18 & 6.75 & 0.0158 \\
\hline EP7860 & $9(493)$ & $24.0 \pm 2.3$ & 0.32 & 0.96 & 8.64 & 0.0072 \\
\hline EP73547 & $9(492)$ & $24.5 \pm 1.9$ & 0.36 & 0.94 & 2.54 & 0.1249 \\
\hline EP6344 & $9(474)$ & $24.6 \pm 1.4$ & 0.93 & 0.50 & 1.50 & 0.2321 \\
\hline$w^{1118}$ & $32(1905)$ & $24.6 \pm 1.0$ & 0.52 & 0.98 & & \\
\hline$h d c^{\mathrm{JK} 910}$ & $26(1618)$ & $23.4 \pm 2.7$ & 0.28 & 1.00 & 72.35 & $<0.0001$ \\
\hline$h d c^{\mathrm{J} 910}$ rescue & $11(458)$ & $24.4 \pm 1.2$ & 0.62 & 0.79 & 0.02 & 0.8861 \\
\hline his $C / 1^{134}$ & $16(1007)$ & $26.1 \pm 1.7$ & 0.55 & 0.91 & 35.66 & $<0.0001$ \\
\hline hisCl1 ${ }^{134}$ rescue & $18(1037)$ & $24.7 \pm 1.2$ & 0.51 & 0.94 & 3.02 & 0.0887 \\
\hline ort $^{P 306}$ & $11(811)$ & $23.5 \pm 2.1$ & 0.23 & 0.99 & 23.68 & $<0.0001$ \\
\hline$o r t^{1}$ & 21 (1479) & $25.5 \pm 3.4$ & 0.74 & 0.78 & 91.20 & $<0.0001$ \\
\hline DKO- $1^{a}$ & 19 (1291) & $23.9 \pm 2.6$ & 0.26 & 1.00 & 49.50 & $<0.0001$ \\
\hline DKO-2 $2^{a}$ & 14 (1288) & $23.2 \pm 2.5$ & 0.19 & 1.00 & 39.04 & $<0.0001$ \\
\hline$w^{1118}$ & $10(573)$ & $24.6 \pm 1.1$ & 0.73 & 0.67 & & \\
\hline ort ${ }^{1}$, ort-Gal4/+ & $11(680)$ & $25.7 \pm 2.8$ & 0.48 & 0.90 & 23.43 & 0.0001 \\
\hline ort $^{1}$, UAS-ort/+ & $11(831)$ & $25.5 \pm 3.8$ & 0.56 & 0.85 & 31.98 & $<0.0001$ \\
\hline ort $^{1}$, ort-Gal4/UAS-ort & $11(549)$ & $24.3 \pm 1.8$ & 0.17 & 1.00 & 6.50 & 0.0202 \\
\hline$w^{1118}, 10 \%$ sucrose & $10(449)$ & $24.3 \pm 1.3$ & 0.21 & 0.99 & & \\
\hline$h d c^{\mathrm{JK} 910}, 10 \%$ sucrose & $10(399)$ & $23.3 \pm 2.8$ & 0.28 & 0.98 & 17.86 & 0.0005 \\
\hline$h d c^{\mathrm{K} 910}, 10 \%$ sucrose, $5 \%$ histamine & $7(292)$ & $24.1 \pm 1.9$ & 0.56 & 0.76 & 2.47 & 0.1371 \\
\hline$w^{1118^{b}}$ & $16(867)$ & $24.7 \pm 1.1$ & 0.74 & 0.74 & & \\
\hline$w^{1118}, 0.4 \mathrm{mg} / \mathrm{m} /$ cimetidine & $20(1318)$ & $25.9 \pm 1.5$ & 0.49 & 0.96 & 11.10 & 0.0021 \\
\hline$w^{1118}, 25 \mathrm{mg} / \mathrm{ml}$ cimetidine & $40(2503)$ & $25.1 \pm 1.6$ & 0.25 & 1.00 & 25.93 & $<0.0001$ \\
\hline$w^{1118}, 500 \mathrm{mg} / \mathrm{ml}$ cimetidine ${ }^{c}$ & $14(741)$ & $22.7 \pm 3.0$ & 0.53 & 0.90 & 31.62 & $<0.0001$ \\
\hline$w^{1118}, 2 \mathrm{mg} / \mathrm{ml}$ hydroxyzine & $28(1817)$ & $23.4 \pm 1.8$ & 0.83 & 0.71 & 5.23 & 0.0272 \\
\hline$w^{1118}, 20 \mathrm{mg} / \mathrm{ml}$ hydroxyzine ${ }^{c}$ & $29(1638)$ & $21.7 \pm 1.9$ & 0.47 & 0.99 & 18.14 & 0.0001 \\
\hline C-S & $10(473)$ & $24.1 \pm 1.4$ & 0.23 & 0.99 & & \\
\hline Cantonized $h d d^{\mathrm{K} 910}$ & $5(278)$ & $22.6 \pm 3.6$ & 0.38 & 0.82 & 46.02 & $<0.0001$ \\
\hline Cantonized hisCl1 ${ }^{134}$ & $10(556)$ & $25.6 \pm 2.0$ & 0.48 & 0.88 & 7.52 & 0.0134 \\
\hline Cantonized ort $^{1}$ & $10(704)$ & $25.6 \pm 2.1$ & 0.19 & 1.0 & 22.82 & 0.0002 \\
\hline
\end{tabular}

ANOVA tests were performed with the SAS (Cary, NC) general linear model. Sensitivity to environmental effects within each genotype was evaluated by examining replicate structure with the model $Y=0$ verall mean + replicate + error. To compare mutant and $w^{1118}$ control flies, the model $Y=$ overall + replicate (genotype) + error was used. $N$, Number of tests; $n$, number of flies tested; DKO, receptor double knock-out of two histamine receptors, $w_{; \prime} ; h_{i s}\left(1^{134}\right.$ and ort ${ }^{1}$. ${ }^{a}$ The significance for $h d c^{\mathrm{J} K 910}$ and DKO-1 or -2 is $p=0.6090$ ( $F=0.27$, ANOVA) or $p=0.1304$ ( $F=2.39$, ANOVA), respectively.

${ }^{b}$ Control flies were placed in a vial containing $0.2 \mathrm{ml}$ of yeast-sucrose paste, except drug.

'The significance for $h d c^{\mathrm{J}}{ }^{\mathrm{k} 910}$ - and cimetidine ( $\left.500 \mathrm{mg} / \mathrm{ml}\right)$-treated fly or hydroxyzine $(20 \mathrm{mg} / \mathrm{ml})$ is $p=0.1232$ ( $F=2.49$, ANOVA) or $p<0.0001$ ( $F=34.06$, ANOVA); $20 \mathrm{mg} / \mathrm{ml}$ hydroxyzine-treated flies, compared with control, showed

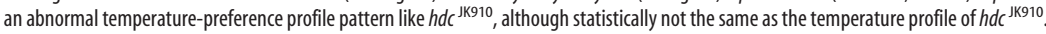

mal temperature preferences of EP7860 and EP24321 were caused by defects in the expression of the $h d c$ gene.

Gisselamnn et al. (2002) reported that there are two histamine receptors in Drosophila, the histamine-gated chloride channels hisCl1 (CG14723) and ort (CG7411). Because EP lines with insertions nearby the gene for the histamine-synthesizing enzyme $H d c$ showed abnormal temperature preferences, we hypothesized that defects in histamine receptors may also cause aberrant temperature-preference behaviors. To test this, two additional EP lines, EP73547 and EP6344, which contain a P element nearby the histamine-gated chloride channels, were selected (Fig. 2C,D). EP73547 has a P element at 33 bp upstream from the $5^{\prime}$ end of hisCl1 gene. The homozygotes for EP73547 were fertile and healthy. EP6344 contains a P element inserted at 1244 bp downstream from the $3^{\prime}$ end of ort gene, and its homozygotes were viable. As we anticipated, abnormal temperature-preference profiles were observed in these lines with $\mathrm{P}$ insertions near histamine receptors, based on PI values (Fig. $2 G-J$ ). These results strongly support the implication of the histamine-signaling genes in temperature preference.

\section{Defects of the histaminergic system cause abnormal temperature preferences}

Although abnormal thermal behaviors were observed in the EP lines having an insertion nearby the histamine-signaling genes, those were not so dramatic compared with two previously re- ported genes, spineless ${ }^{\text {aristapedia }}$ and bizarre (Sayeed and Benzer, 1996). This could be attributable to the tested alleles being hypomorphes. Therefore, we decided to examine temperature preferences of the null or strong hypomorphic mutants of these genes. Because no known hisCl1 mutant was available, hisCl1 deletion mutants were generated through imprecise excision with EP73547. From $\sim 500$ excised lines screened, seven were confirmed as hisCl1 deletion mutants using PCR analysis against genomic DNA. We chose his Cl1 ${ }^{134}$ (1.7 kb deletion; three transmembrane domains were deleted including a ligand binding domain) for additional studies (Fig. 2C). To confirm that hisCl1 mRNA was not expressed from his $\mathrm{Cl}^{134}$, RT-PCR was performed using total RNA extracted from the mutant. As shown in Figure $4 \mathrm{H}$, hisCl1 ${ }^{134}$ gave no PCR signals. $h d c^{\mathrm{JK} 910}$ (kindly provided by Dr. Pak) is a loss-of-function mutant of histidine decarboxylase (Burg et al., 1993) expressing very low levels (10-fold less than wild type) of histamine synthesis activity (Sarthy, 1991). ort $^{\mathrm{P} 306}$ is a hypomorphic allele of the histamine receptor that expresses a very low level of transcript $(<30 \%$ compared with wild type) (Gengs et al., 2002).

With these mutants in our hands, we then assayed their temperature-sensing performance. $h d c^{\mathrm{JK} 910}$ showed an altered temperature-preference profile ( $p<0.0001$; ANOVA), in which $\mathrm{PI}_{\text {Low }}$ and $\mathrm{PI}_{\mathrm{High}}$ values were reduced significantly compared with wild type (Fig. $3 B$, asterisks). In $h d c^{\mathrm{JK} 910}$, PI indices to low and high temperature were decreased to $\sim 0.40 \pm 0.04$ and $0.56 \pm$ 
0.05 , respectively ( $p<0.0001 ; t$ test), compared with wild type. In other words, preference for the intermediate temperature was lowered, and more flies populated both the low- and hightemperature areas than wild type. Interestingly, the hisCl1 null mutant his $\mathrm{Cl1}^{134}$ showed reduced avoidance only to high temperature, or thermophilic behavior $\left(\mathrm{PI}_{\text {Low }}=0.89 \pm 0.04, p>\right.$ $0.01, t$ test; $\mathrm{PI}_{\mathrm{High}}=-0.10 \pm 0.09, p<0.0001, t$ test) (Fig. $3 A, B$ ). On the other hand, ort ${ }^{\mathrm{P} 306}$ appeared to have reference for low temperature rather than high temperature $\left(\mathrm{PI}_{\text {Low }}=0.56 \pm 0.06\right.$, $p<0.001, t$ test; $\left.\mathrm{PI}_{\mathrm{High}}=0.78 \pm 0.04, p>0.001\right)($ Fig. $3 A, B)$.

It was interesting that the hisCl1 null mutant and ort hypomorph mutant showed different temperature preferences for high and low temperature, and $h d c^{\mathrm{JK} 910}$ had a temperature preference that included behavioral features of both histamine receptors. These results prompted us to test the possibility that the Ort receptor regulates cold-temperature preference and $\mathrm{HisCl1}$ receptor controls high-temperature preference. We performed the preference assay on the ort ${ }^{1}$ null mutant to address whether the ort null phenotype is similar to the ort strong hypomorph ort ${ }^{\mathrm{P} 306}$. Unexpectedly, the ort ${ }^{1}$ null mutant showed a preference for high temperature $\left(\mathrm{PI}_{\text {Low }}=0.46 \pm 0.06, p<0.0001, t\right.$ test; $\mathrm{PI}_{\mathrm{High}}=$ $-0.04 \pm 0.08, p<0.0001, t$ test) (Fig. $3 B$ ). This result suggests that although histamine receptors have certain effects on determining preference for temperature, histamine receptors might not regulate preference by means of separating assigned temperature ranges (specifically, ort might have a role in regulating cold and hisCl1 might have a role in regulating hot). The mechanism for the discrepancy between ort ${ }^{\mathrm{P} 306}$ hypomorphic and ort $^{1}$ null mutants cannot be explained with certainty. However, it can be inferred that the precise expression level and/or precise distribution of histamine receptors in the neurons regulating temperature preference may be critical for normal histamine function.

There were obvious differences in preference pattern between $h d c^{\mathrm{JK} 910}$ and each histamine receptor. This might be attributable in part to receptor gene redundancy. Thus, if both receptors were eliminated together, flies should show a similar or consistent preference for temperature. To test whether flies lacking both of the histamine receptors [ort and hisCl1 double knock-out (DKO)] show phenotypes similar to the $h d c^{\mathrm{JK} 910}$ null mutant, a DKO was generated from the recombination of his $\mathrm{Cl}^{134}$ and ort $^{1}$. Two independent DKO lines (DKO-1 and -2) showed phenotypes very similar to $h d c$ null mutants (Fig. 3C). The correlations between $h d c^{\mathrm{JK} 910}$ and DKO-1 or DKO-2 were $p=0.6090$ and $p=0.1304$ (ANOVA), respectively, and PI values were similar (Fig. 3D).

Because muscle activity or locomotor behaviors might influence the results of our temperature-preference assay, we examined the motor activities of the histaminergic mutants in three representative temperature conditions $\left(15,25\right.$, and $\left.32^{\circ} \mathrm{C}\right)$ using the flight assay method (Fig. 3E) (Pesah et al., 2005). When comparing the flight index at 15 or $32^{\circ} \mathrm{C}$ and the index at $25^{\circ} \mathrm{C}$, most of the mutants tested had no significant differences in motor activity $(p>0.01)$, suggesting the abnormal temperature behaviors in the mutants are not from the defects in motor activity.

We used $w^{1118}$ as a control fly because $w^{1118}$ showed almost the same temperature-preference profile ( $p=0.0986$; ANOVA) and PI values compared with Canton S (C-S) (Fig. $3 A, B, F, G$ ). However, this does not completely exclude the possibility that abnormal temperature preferences, caused by the defects in the histamine-signaling genes, are affected by a white-eye genetic background $\left(w^{1118}\right)$. Therefore, we outcrossed $h d c^{\mathrm{JK} 910}$, his Cl1 ${ }^{134}$, and ort $^{1}$ mutants to C-S. After four generations of outcrossing to C-S, we examined the temperature preference of


Figure 6. The histaminergic mutants show a low tolerance for high temperature. $\boldsymbol{A}$, The histaminergic mutants showed low tolerance for high temperature. The histaminergic mutants were placed on an aluminum block of fixed temperature $\left(40^{\circ} \mathrm{C}\right)$, and the number of knock-down flies was recorded at 30 s intervals with a digital camera. All of the histaminergic mutants were knocked down faster than wild-type control flies. DKO-res is a DKO mutant expressing transgenes for both histamine receptors. $\boldsymbol{B}$, The histaminergic mutants showed a much delayed arousal time after heat shock compared with control. C, Data from 30 and $180 \mathrm{~min}$ in $\boldsymbol{B}$ were extracted and reconstituted in the histogram. ${ }^{*}$ No significant difference compared with control ( $t$ test); ${ }^{* *} p<0.001$ compared with control ( $t$ test). Error bars indicate SEM.

each cantonized mutant. Temperature preferences of cantonized $h d c^{\mathrm{JK} 910}$ and his $\mathrm{Cl1}^{134}$ mutants were very similar to those of the corresponding mutants in the $w^{1118}$ background (Fig. 3F, G), although the cantonized ort ${ }^{1}$ mutant showed an increased PI in the low-temperature region. These data indicate that the histaminergic system has a role in regulating temperature preference in Drosophila regardless of their genetic backgrounds.

Collectively, our results indicate that the histaminergic system in Drosophila is involved in controlling the temperature preference. However, the effects on temperature preference, caused by the null alleles of the histamine-signaling genes, are not as marked as the bizarre mutant (Sayeed and Benzer, 1996). This indicates that histamine and its receptors may have a role in fine-tuning temperature preference rather than centrally determining or controlling it. 


\section{Altered temperature preferences in the histaminergic mutants are restored by genetic and pharmacological rescue experiments}

If the histamine-signaling genes primarily cause abnormal temperature preferences, their mutants should show rescued normal preference for temperature when genetic functions are restored. To address whether altered temperature preferences exhibited in our mutants of the histaminesignaling genes were caused by defects in the histamine-signaling genes themselves, transgenic flies containing genomic DNA rescue fragments (for $h d c$, ort, and hisCl1 mutants), UAS-ort, and ort-Gal4 were created. $h d c$, hisCl1, and ort genomic rescue constructs were injected into embryos of the corresponding mutants as described in

Materials and Methods. The UAS-ort transgene was driven under the control of ort-Gal4 in an ort null background. Each mutant fly $\left(h d c^{\mathrm{JK} 910}\right.$, his $\mathrm{Cl1}^{134}$, and ort ${ }^{1}$ ) transformed with the corresponding transgenes showed restored normal temperature-preference profiles, as expected ( $p>0.01$ vs $w^{1118}$; ANOVA) (Fig. $\left.4 A-F\right)$. Transgenes were expressed normally in the transformed mutants as determined by immunohistochemistry and RT-PCR (Fig. 4G,H; see Fig. 9C).

Previous data showed that histamine-deficit mutants with a defective electroretinogram phenotype can be rescued by administration of histamine (Melzig et al., 1998). To assess whether altered temperature preference in the $h d c$ mutant can also be restored by histamine treatment, the $h d c^{\mathrm{JK} 910}$ mutant was fed with $5 \%$ histamine for $1 \mathrm{~d}$ and assayed. As shown in Figure $4 \mathrm{~A}$, the phenotype of $h d c^{\mathrm{JK} 910}$ was significantly rescued by histamine feeding ( $p=0.1371$ vs $w^{1118}$; ANOVA), although there were some imperfect matches in profile pattern and $\mathrm{PI}_{\text {Low }}(p=0.002$ of $\mathrm{PI}_{\text {Low }} ; t$ test) (Fig. $4 A, B$ ) compared with controls. This imperfect match might be attributable to poor histamine reuptake in fly brains (Melzig et al., 1998). Together, these results indicate that altered temperature preferences in the mutants of histamine signaling result solely from the functional defects in the histaminesignaling genes.

\section{Histamine receptor antagonists cause the $h d c$ null mutant- like abnormal temperature preferences}

It was reported that compounds able to competitively inhibit histamine receptors in humans, such as cimetidine and hydroxyzine, can effectively inhibit fruit fly histamine receptors in vivo and ex vivo (Gisselmann et al., 2002; Shaw et al., 2000). Therefore, we tested whether wild-type flies treated with these inhibitors show altered temperature preferences like the $h d c$ null mutant or receptor DKO. Interestingly, when treated with 500 $\mathrm{mg} / \mathrm{ml}$ cimetidine and $20 \mathrm{mg} / \mathrm{ml}$ hydroxyzine, wild-type flies showed $h d c$ null or receptor DKO-like behaviors (Fig. $5 \mathrm{~A}, \mathrm{~B}$; Table 1). These pharmacological results further confirm that histamine has a role in determining temperature preference in Drosophila.

\section{The histaminergic mutants show a low tolerance for hot temperature but a high tolerance for cold temperature} Organisms, including insects, have an endurable maximum and minimum temperature for surviving. These thermal limits (torpor occurs at or beyond these temperatures) or "critical thermal limits" can be adjusted or reset according to accommodated environmental or physiological conditions (Kelty and Lee, 1999; for review, see Bale, 2002; Shreve et al., 2004). Given that changes in temperature preference occur in the range of critical thermal limits (Hedgecock and Russell, 1975), it is possible that the mechanism causing changes of temperature preference might also adjust the range of critical thermal limits at the same time (or in parallel). To address whether alteration in temperature preference caused by the defects in the histamine-signaling genes could influence the range of critical thermal limits, we examined tolerance changes for high and low temperature in their mutants.

First, the tolerance for high temperature was examined. For this, we placed the histaminergic mutants on the aluminum block of fixed temperature $\left(40^{\circ} \mathrm{C}\right)$ and recorded the number knockeddown at $30 \mathrm{~s}$ intervals. All of the histaminergic mutants were knocked-down faster than control flies (Fig. 6A). We then measured the recovery time for arousal of the knock-down flies. To assay this, the vials containing flies were put into a water bath fixed at $40-41^{\circ} \mathrm{C}$ for $10 \mathrm{~min}$; the vials were then removed from the bath and placed at room temperature. Aroused flies were counted immediately and at 2 min intervals (Fig. $6 \mathrm{~B}$ ). The recovery time for the histaminergic mutants was much delayed compared with the control. Only $20-40 \%$ of the histaminergic mutants knocked-down were able to wake up within $30 \mathrm{~min}$ after they returned to room temperature (Fig. 6C). After $3 \mathrm{~h}$, all flies were aroused from a heat shock-induced coma. These results suggest that the defects in the histamine-signaling genes can cause low tolerance for high temperature or lowering the upper thermal limit.

To confirm whether the low tolerance to high temperature in the $h d c$ mutant and DKO is caused by defects in histamine function, genetic rescue experiments on the DKO mutant were performed. First, two DKO mutants with each of genomic transgenes for histamine receptors were created. Then each transformed DKO was crossed with each other to generate a DKO with both of the histamine receptor (DKO-res) genes. When DKO-res was tested, we observed considerably rescued phenotypes compared with DKO (Fig. 6). These results suggest that the defects in the histamine-signaling genes caused a low tolerance to high temperature.

Second, a chill-coma recovery test of adult flies at $0^{\circ} \mathrm{C}$ and a tolerance test for cold stress at $4^{\circ} \mathrm{C}$ were performed to examine tolerance to cold temperature in the histaminergic mutants. Tolerance for cold stress was tested by maintaining 10 flies in a $4^{\circ} \mathrm{C}$ 
Table 2. Statistical analysis of the variance for tolerance for low and high temperature

\begin{tabular}{|c|c|c|c|c|c|}
\hline \multirow[b]{2}{*}{ Genotype } & \multirow[b]{2}{*}{$N(n)$} & \multicolumn{2}{|c|}{ Comparing within replicates } & \multicolumn{2}{|c|}{ Comparing with control } \\
\hline & & $F$ value & $p$ value & $F$ value & $p$ value \\
\hline \multicolumn{6}{|l|}{ Tolerance to cold stress at $4^{\circ} \mathrm{C}$} \\
\hline$w^{1118}$ & $12(120)$ & 0.57 & 0.84 & & \\
\hline$h d d^{\mathrm{K} 910}$ & $12(120)$ & 1.73 & 0.13 & 17.38 & 0.0004 \\
\hline hisC/1 ${ }^{134}$ & $12(120)$ & 0.17 & 1.00 & 0.00 & 1.0000 \\
\hline ort $^{1}$ & $12(120)$ & 0.08 & 1.00 & 0.02 & 0.8786 \\
\hline DKO & $12(120)$ & 0.38 & 0.95 & 17.33 & 0.0004 \\
\hline DKO-res & $14(140)$ & 0.14 & 1.00 & 0.00 & 0.9825 \\
\hline \multicolumn{6}{|c|}{ Viability assay after $0^{\circ} \mathrm{C}$ cold shock } \\
\hline$w^{1118}$ & $5(50)$ & 0.11 & 0.97 & & \\
\hline$h d d^{\mathrm{K} 910}$ & $5(50)$ & 0.55 & 0.70 & 48.36 & 0.0001 \\
\hline DKO & $5(50)$ & 0.91 & 0.50 & 12.36 & 0.0097 \\
\hline DKO-res & $10(100)$ & 0.32 & 0.95 & 0.61 & 0.4496 \\
\hline \multicolumn{6}{|c|}{ Histamine intake and cold tolerance } \\
\hline$w^{1118}, 0$ mm histamine & $5(50)$ & 1.02 & 0.40 & & \\
\hline$w^{1118}, 1$ mm histamine & $5(50)$ & 1.01 & 0.41 & 6.82 & 0.0310 \\
\hline$w^{1118}, 10$ mm histamine & $5(50)$ & 1.37 & 0.16 & 3.43 & 0.1013 \\
\hline$w^{1118}, 100 \mathrm{~mm}$ histamine & $5(50)$ & 0.17 & 0.96 & 81.98 & $<0.0001$ \\
\hline$w^{1118}, 250 \mathrm{~mm}$ histamine & $5(50)$ & 0.36 & 0.83 & 198.20 & $<0.0001$ \\
\hline
\end{tabular}

ANOVA tests were performed with the SAS general linear model. $N$, Number of tests; $n$, number of flies tested.

cold chamber. For the first few days, there were no differences in survival rates between controls and the histaminergic mutants (Fig. 7A, black and white bars). However, $h d c^{\mathrm{JK} 910}$ and DKO showed $>80 \%$ survival at day 6 , whereas the others were $<50 \%$ (Fig. $7 A$, gray bars). When the histamine receptor function was restored in DKO (DKO-res), survival at $4^{\circ} \mathrm{C}$ was returned to a the control level (Fig. 7A, Table 2) ( $p>0.001$; ANOVA). This result showed that tolerance to cold stress was increased in the mutants without histamine functions ( $h d c^{\mathrm{JK} 910}$ and DKO). To check recovery time from cold coma, a chill-coma recovery test at $0^{\circ} \mathrm{C}$ was performed (Fig. 7B). Control, hisCl1 ${ }^{134}$, and ort ${ }^{1}$ showed no difference in arousal time from cold coma (data not shown). However, $h d c^{\mathrm{JK} 910}$ and DKO showed dramatic increases in recovery rates from cold coma (Fig. $7 B$, double asterisks; Table 2$)(p<$ 0.01 ; ANOVA). When the histaminergic function was restored (DKO-res), the enhanced ability to recover from cold coma ceased (Fig. $7 B$, single asterisk) ( $p>0.01$; ANOVA). The results in Figure 7 show that tolerance to low temperature was increased only when histamine functions were absolutely ablated. Thus, it could be inferred that tolerance to low temperature was reduced when histamine secretion was increased in Drosophila. To test this, we administered histamine to control flies $\left(w^{1118}\right)$ for $24 \mathrm{~h}$ and incubated them in ice $\left(0^{\circ} \mathrm{C}\right)$ for $18 \mathrm{~h}$. After that, flies were placed at room temperature and aroused flies were counted at 5 min intervals. Interestingly, the recovery rate from chill-coma in histamine-ingested flies was significantly delayed in a concentration-dependant manner (Fig. 8), indicating that histamine has an adverse effect on cold tolerance in Drosophila. Collectively, these results suggest that a complete defect in histamine signaling causes tolerance to low temperature or decreases the lower thermal limit. One receptor defect mutant had no tolerance to cold compared with control. This may be attributable to gene redundancy in histamine receptors. Compared with tolerance to high temperature, this fact could indicate mechanistic differences between generating tolerance to low and high temperature or in setting up the upper and lower thermal limits.

\section{Distribution of histamine and its receptors in adult brain}

Defects in the histamine-signaling genes showed abnormal temperature preferences and altered tolerance to low and high temperature (or altered critical thermal limits). To address which neurons or brain regions are involved in these processes, we examined the spatial expression patterns of the histaminesignaling genes.

To localize histamine and histaminemaking cells, histamine antiserum was used. Despite the small number $(\sim 18-24)$ (for review, see Nässel, 1999) of cell bodies stained by histamine antibodies, heavily stained arborizations of histaminergic fibers were found throughout the brain (Fig. $9 A, C)$. Strong histamine expression in optic lobes and ocelli are consistent with its established functions, such as neurotransmitter for photoreceptor. The pedunculi of mushroom bodies were surrounded by a dense network of immunoreactive arborizations (Fig. 9A,C). These distributions of histamine suggest that besides photoreception, histamine might have another function, especially determining temperature preference, in the CNS.

To locate ort distribution, ISH and immunohistochemistry using Ort antiserum were performed. The ort transcript and protein were distributed in the lamina (Fig. 9D-F), medulla (Fig. $9 D-F$ ), ocellar postsynaptic interneurons (Fig. $9 E$, brackets, $I, L$ ) (also known as L-type interneurons), pars intercerebralis (Fig. 9G-I), fan-shaped body (FB) (Fig. 9G, blue arrowhead), unknown cells in the lateral and central brain (Fig. 9G, white arrowhead, $M$, white arrowheads in the ventral region), and thoracic ganglia (Fig. 9J, asterisk, Q). The prominent presence of the ort transcript and protein in the lamina, medulla, and ocellar postsynaptic interneuron indicate its primary role in photoreceptor synaptic transmission. Ort protein-expressing axons were found in the posterior slope [a high-order ocellar center as well as a premotor center (Mizunami, 1995a,b)] (Fig. 9G). Our data suggest that neurons or brain regions not related to visual functions are involved in determining temperature preference or tolerance to low and high temperature.

The tissue distribution of another histamine receptor, hisCl1, was examined using antiserum against recombinant HisCl1 protein. $\mathrm{His} C l 1$ protein was distributed in many neurons including pars intercerebralis, suboesophageal ganglia (Fig. 9N, SOG), lateral protocerebrum (Fig. 9N, arrowheads), dorsal neurons (Fig. $9 N$, open arrow), and thoracic ganglia (Fig. 9Q), as well as regions including the $\mathrm{FB}$, esophageal foramen (OF), and the optic lobe medulla (Fig. 9N, inset). Unexpectedly, HisCl1 protein was not colocalized with Ort protein in many brain regions (Fig. 90). Visual postsynaptic neurons in the optic lobe and L-type interneurons in the superior protocerebrum, expressing Ort protein strongly, did not show any HisCl1-positive signals. These results suggest that $\mathrm{HisCl1}$ protein may have no visual function. Of course, we cannot exclude the possibility that $\mathrm{HisCl1}$ is indirectly involved in visual functions because there are $\mathrm{HisCl1}$-positive signals in optic lobes (Fig. 9N, inset). There were only a few neurons coexpressing both histamine receptors. Both receptors were coexpressed in two dorsolaterally located large neurons in each hemisphere (Fig. 90, white arrow and inset). Each neuron had a long projection into the superior protocerebrum, probably near the intrinsic mushroom body cells (Kenyon cells; Fig. 9O, red arrowheads). Also, the codistributions of Ort and HisCl1 protein in $\mathrm{FB}, \mathrm{OF}$, and several cells of the thoracic ganglia were observed (Fig. 9N, O,Q). Coexpression patterns of two histamine 

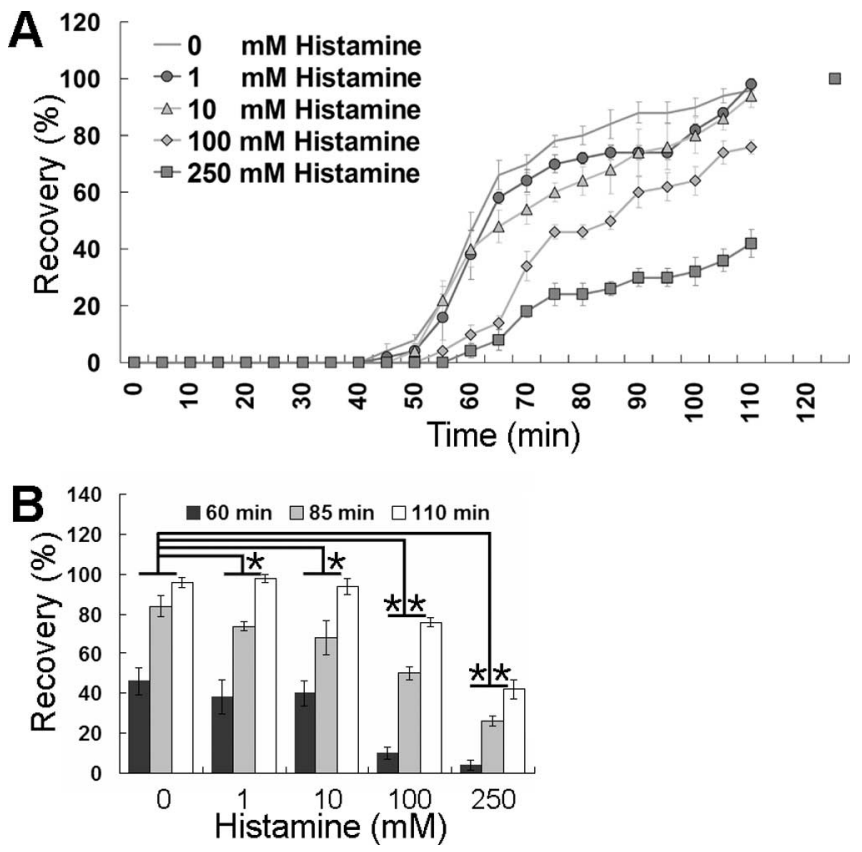

Figure 8. Decreased cold tolerance by histamine intake. $A$, Recovery of $w^{1118}$ control flies from chill-coma $\left(0^{\circ} \mathrm{C}\right)$ was delayed by histamine administration in a concentration-dependent manner. This result is consistent with the aforementioned result. $\boldsymbol{B}$, Data from 60,85 , and 110 min in $A$ are extracted and reconstituted in the histogram. *No significant difference compared with control (ANOVA); ${ }^{* *} p<0.001$ compared with control (ANOVA). Error bars indicate SEM.

receptors suggest that dorsolaterally located neurons, neurons in the thoracic ganglia, FB (a part of the central complex; higher control center), OF (axons of pars intercerebralis neurosecretory cells are converged), and pars intercerebralis may participate in the mechanism by which temperature preference and cold tolerance are regulated.

Notably, the locations of HisCl1-expressing cells in the lateral protocerebrum seemed to be similar to the location of clock cells, especially lateral neurons (LN) (Kaneko and Hall, 2000; HelfrichFörster, 2005). Thus, we performed double immunostaining with Period (Per) antiserum to address whether hisCl1 was expressed in LNs. As shown in Figure 9P, His Cl1 was expressed in four large ventral LNs among LNs. Because circadian clock neurons can affect temperature preference (Hyun et al., 2005), this result suggests the possibility that histamine may affect temperature preference by way of modulating these clock neurons.

Recently, it was reported that neurons expressing $A T R P A 1$ in the fruit fly CNS are essential regulators of thermotaxis (Rosenzweig et al., 2005). Thus, it can be inferred that histamine might be secreted by these neurons to modulate temperature preference or histamine might modulate neural activity of these neurons. To verify whether the histamine-signaling genes were expressed in dTRPA1-positive cells, we performed immunohistochemistry to detect HisCl1, Ort, and histamine in dTRPA1-driven UAS-lacZ flies (Fig. 9R,S; data not shown in the case of anti-Ort). These results show that neither histamine receptors nor histamine is detectable in $A T R P A 1$-expressing cells. Therefore, this result indicates that histamine is not involved in the temperaturepreference-determining mechanism controlled by dTRPA1expressing neurons.

\section{Discussion}

The histaminergic mutants showed abnormal temperature preferences, which were rescued by restoring corresponding gene functions. This finding indicates that the histamine-signaling genes function by controlling preference for temperature. However, preference profile changes in these histaminergic mutants were weaker than previously reported thermosense mutants such as spineless ${ }^{\text {aristapedia }}$, bizarre, and dTRPA1(RNAi) (Sayeed and Benzer, 1996; Rosenzweig et al., 2005). Furthermore, the histamine-signaling genes were not coexpressed with dTRPA1, suggesting that histamine, as an essential element for thermotaxis, might be insufficient to function as a central regulator to control temperature preference but finely modulates the temperature preference in Drosophila.

This is the first report clearly showing spatial expression patterns of histamine receptors. Compared with previous reports, we observed some unique features. (1) Gisselmann et al. (2002) and Zheng et al. (2002) showed that Ort and HisCl1 could be assembled into functional homomultimers or heteromultimers. They reported that the histamine binding affinity of the heteromultimeric receptors is higher than that of homomultimers. Because neurons with both receptors can respond to low levels of histamine, it is possible they have a more critical role in controlling various biological functions than the singly expressing ones. Accordingly, newly identified neurons and brain regions, expressing both receptors (such as FB, OF, dorsolateral neurons, and pars intercerebralis), may have critical roles in determining temperature preference. Consistent with this hypothesis, we found that defects in the central complex cause abnormal temperature preferences (our unpublished observations). (2) Another interesting finding is that Ort is used as major postsynaptic receptors in visual processing, whereas $\mathrm{HiSCl1}$ is not. In contrast to $\mathrm{Ort}$, HisCl1 was not expressed in the postsynaptic neurons of photoreceptors. For this reason, the hisCl1 mutant with defects in visual functions might not be recognized in the previous experiments for screening visual defective mutants (Gengs et al., 2002). (3) Finally, hisCl1 is expressed in circadian clock neurons. Recently, several reports showed that changes in environmental temperature could directly control the circadian clock (Sawyer et al., 1997; Sidote et al., 1998; Majercak et al., 1999; Glaser and Stanewsky, 2005). In addition, our previous data suggested that clock neurons can affect temperature preference in Drosophila (Hyun et al., 2005). These results imply that thermal behaviorcircadian rhythm in Drosophila might be interlocked like the mammalian POA/anterior hypothalamus (an important site for thermoregulation) and suprachiasmatic nucleus (a clock for timing circadian rhythms) (for review, see Saper et al., 2005).

The histaminergic mutants showed changes in tolerance to low and high temperatures as well as temperature preference. Tolerance to low and high temperature is affected by critical thermal limits (Kelty and Lee, 1999; Bale, 2002). To survive in the range of the thermal limit, critical thermal limits must be regulated according to changes in preferring temperature or accommodated temperature. From this point of view, changes in thermal limits accompanying temperature preference in the histaminergic mutants are quite probable. Drosophila showed an increase in cold tolerance and a decrease in hot tolerance when there are defects in histamine function. This coincides with previous reports that resetting the lower thermal limit may come at the expense of a corresponding decrease in the upper thermal limit (Bale, 2002; Shreve et al., 2004).

Our study demonstrates that histamine plays important roles in temperature preference and tolerance to low and high temperature, roles that extend beyond its well accepted activity in visual reception, mechanosensory reception, and sleep. This study pro- 

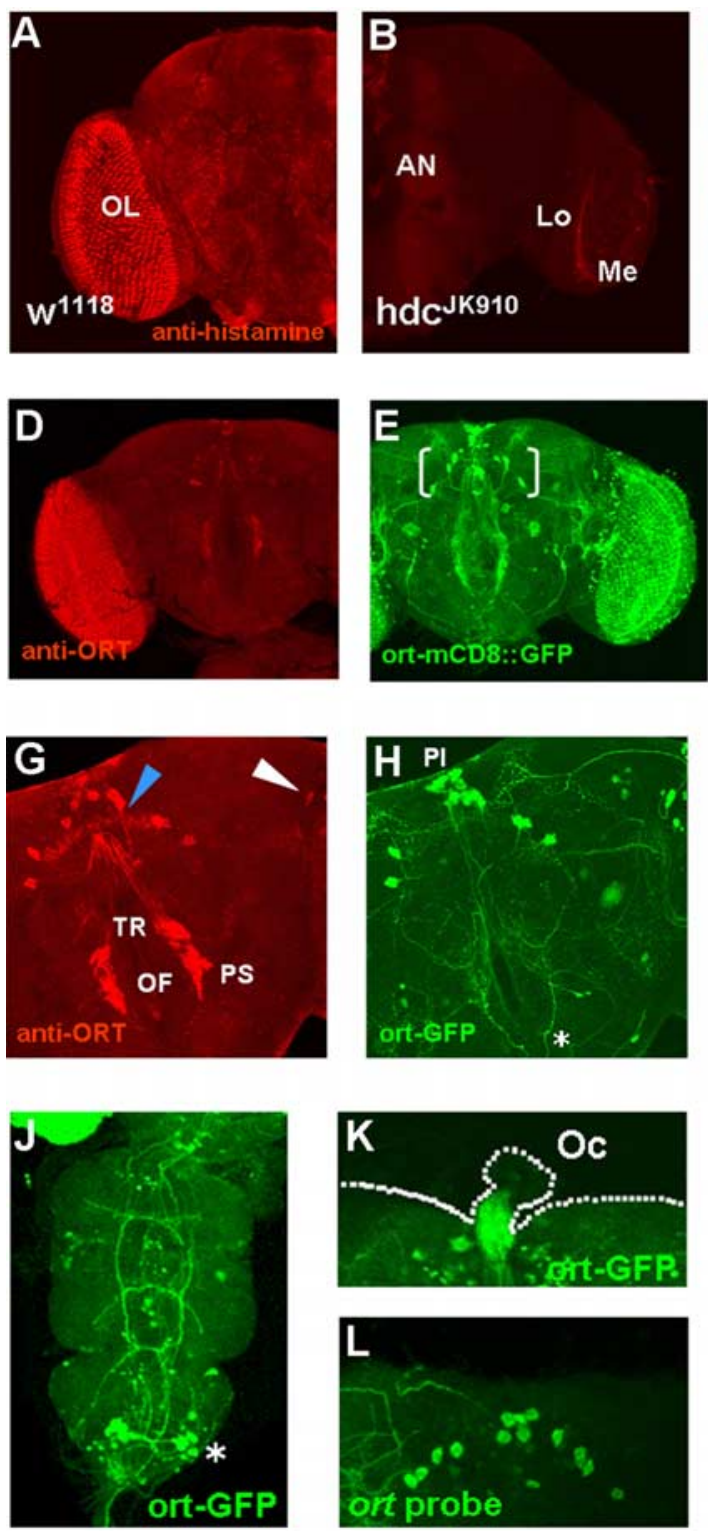
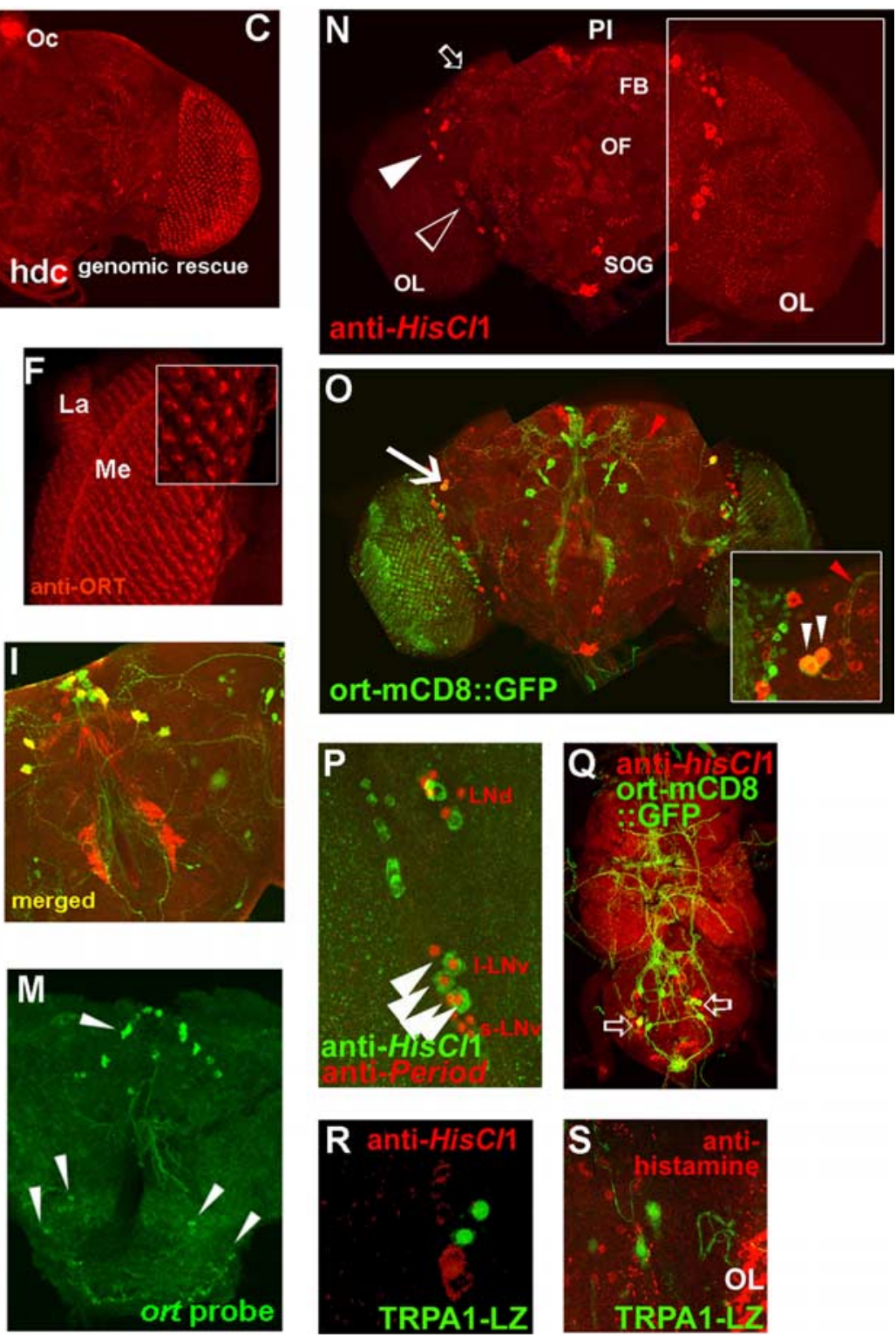

Figure 9. The expression patterns of the genes for histamine signaling. $A-C$, Histamine distribution in adult brain. $A$, Heavily stained arborizations of histaminergic fibers were found throughout large parts of the brain. $\boldsymbol{B}, h d c^{\mathrm{J} K 910}$ null mutants have no or very low histamine immunoreactivity. $C$, $h d c^{\mathrm{J} K 910}$-rescue containing $12.5 \mathrm{~kb}$ of the $h d c$ genomic fragment expressed $h d c$ protein properly. $\boldsymbol{D}-\boldsymbol{M}$, The tissue distribution of the ort gene. $\boldsymbol{D}$, Ort protein was prominently expressed in the optic lobe and L-type interneurons (ocellar postsynaptic interneuron; brackets in $\boldsymbol{E}$ ). $\boldsymbol{E}$, ort-Gal4/UAS-mCD8::GFP. F, Ort protein was expressed in the lamina (fragmented) and the medulla of the optic lobe. The inset in $\boldsymbol{F}$ showed magnified postsynaptic cells in the medulla. $\mathbf{G}-\mathbf{I}$, Ort protein distribution in the central brain region. Ort proteins were distributed in L-type postsynaptic interneurons, pars intercerebralis, FB (blue arrowhead), the posterior slope, $0 F$, tritocerebrum, and unknown lateral cells ( $\boldsymbol{G}$, white arrowhead). Some Ort-positive axons were connected to the thoracic ganglia via cervical connectives ( $\boldsymbol{H}$, asterisk). $\boldsymbol{H}$, ort-gal4/UAS-GFP. I, Merged image of $\boldsymbol{G}$ and $\boldsymbol{H}$. Some cells did not overlap. J, Ort-positive cells in the thoracic ganglia (asterisk). Anterior is up, and the ventral view is shown. $\boldsymbol{K}$, Ort is located in the postsynaptic cell of ocelli. Dorsal is up. Brain and ocelli are delineated with the dotted line. $\boldsymbol{L}, \boldsymbol{M}$, ort ISH. A fluorescein-labeled antisense ort riboprobe was used. $\boldsymbol{L}$, At least 15 cells (L-type neuron) were labeled prominently. $\boldsymbol{M}$, In addition to L-type neurons, at least four neurons were detected in the ventral brain region (arrowheads). $\mathbf{N} \mathbf{Q} \mathbf{Q}$, The distribution of $\mathrm{His} \mathrm{Cl}$ protein in adult brain. $\mathbf{N}$, His $/ 1$ proteins (red) were distributed in pars intercerebralis, suboesophageal ganglia, FB, OF, dorsal neurons (open arrow), lateral brain region (white and open arrowheads), optic lobe, and central brain region. The optic lobe was magnified (inset). His $(11$ was not expressed in postsynaptic neurons in the medulla. $\mathbf{0}$, The relative positions between $\mathrm{Ort}$ and $\mathrm{His}(17 \mathrm{protein}$ distribution. The inset is a magnified region denoted by the arrow, where $\mathrm{His}(11$ and Ort were coexpressed in two neurons dorsolaterally located (white arrowheads in inset). These neurons showed projections into the dorsocentral brain region (red arrowheads). Interestingly, there were seldom neurons that coexpressed His $/ 1$ and Ort proteins. P, Four neurons expressing His (I1 protein (green) in the lateral brain region coexpressed Per protein (red), which indicates that these HisC11-positive neurons are large ventrolateral neurons (white arrowheads). Dorsal is up. $\mathbf{Q}$, ort-Gal4/UAS-mCD8::GFP (green) and HisC11-positive cells (red) in the thoracic ganglia. Both receptors are expressed in a few cells (open arrows). Anterior is up, and the ventral view is shown. $\boldsymbol{R}, \mathbf{S}$, dTRPA1, an essential regulator of thermotaxis, expressing cells (green) showed no expression of histamine neurotransmitter or histamine receptors HisCl1 and Ort (data not shown). OL, Optic lobe; AN, antennal lobe; Lo, lobula; Me, medulla; La, lamina; OC, ocelli; PI, pars intercerebralis; PS, posterior slope, TR, tritocerebrum; SOG, suboesophageal ganglia.

vides us with new insight into the mechanism of temperature sensing or thermotactic decisions in Drosophila. Regulation of histamine secretion may help to control physiological responses such as rapid cold hardening or seasonal acclimation that occur according to changes in temperature and light. Given the poten- tial relationship between temperature and the circadian clock, this work could provide clues for additional insight into sleep and arousal. Finally, this study will help pave the way toward a better understating of the molecular mechanisms and neural circuits of temperature preference as well as the critical thermal limit. 


\section{References}

Bale JS (2002) Insects and low temperatures: from molecular biology to distributions and abundance. Philos Trans R Soc Lond B Biol Sci 357:849-862.

Boulant JA (2000) Role of the preoptic-anterior hypothalamus in thermoregulation and fever. Clin Infect Dis 31 [Suppl 5]:S157-S161.

Burg MG, Sarthy PV, Koliantz G, Pak WL (1993) Genetic and molecular identification of a Drosophila histidine decarboxylase gene required in photoreceptor transmitter synthesis. EMBO J 12:911-919.

Claiborne BJ, Selverston AI (1984) Histamine as a neurotransmitter in the stomatogastric nervous system of the spiny lobster. J Neurosci 4:708-721.

Gengs C, Leung HT, Skingsley DR, Iovchev MI, Yin Z, Semenov EP, Burg MG, Hardie RC, Pak WL (2002) The target of Drosophila photoreceptor synaptic transmission is a histamine-gated chloride channel encoded by ort (hclA). J Biol Chem 277:42113-42120.

Gisselmann G, Pusch H, Hovemann BT, Hatt H (2002) Two cDNAs coding for histamine-gated ion channels in D. melanogaster. Nat Neurosci 5:11-12.

Glaser FT, Stanewsky R (2005) Temperature synchronization of the Drosophila circadian clock. Curr Biol 15:1352-1363.

Goto SG, Kimura MT (1998) Heat- and cold-shock responses and temperature adaptations in subtropical and temperate species of Drosophila. J Insect Physiol 44:1233-1239.

Gray JM, Karow DS, Lu H, Chang AJ, Chang JS, Ellis RE, Marletta MA, Bargmann CI (2004) Oxygen sensation and social feeding mediated by a C. elegans guanylate cyclase homologue. Nature 430:317-322.

Haas H, Panula P (2003) The role of histamine and the tuberomamillary nucleus in the nervous system. Nat Rev Neurosci 4:121-130.

Hardie RC (1989) A histamine-activated chloride channel involved in neurotransmission at a photoreceptor synapse. Nature 339:704-706.

Hedgecock EM, Russell RL (1975) Normal and mutant thermotaxis in the nematode Caenorhabditis elegans. Proc Natl Acad Sci USA 72:4061-4065.

Helfrich-Förster C (2005) Neurobiology of the fruit fly's circadian clock. Genes Brain Behav 4:65-76.

Hyun S, Lee Y, Hong ST, Bang S, Paik D, Kang J, Shin J, Lee J, Jeon K, Hwang S, Bae E, Kim J (2005) Drosophila GPCR Han is a receptor for the circadian clock neuropeptide PDF. Neuron 48:267-278.

Iovchev M, Kodrov P, Wolstenholme AJ, Pak WL, Semenov EP (2002) Altered drug resistance and recovery from paralysis in Drosophila melanogaster with a deficient histamine-gated chloride channel. J Neurogenet 16:249-261.

Kaneko M, Hall JC (2000) Neuroanatomy of cells expressing clock genes in Drosophila: transgenic manipulation of the period and timeless genes to mark the perikarya of circadian pacemaker neurons and their projections. J Comp Neurol 422:66-94.

Kelty JD, Lee Jr RE (1999) Induction of rapid cold hardening by cooling at ecologically relevant rates in Drosophila melanogaster. J Insect Physiol 45:719-726.

Kimura KD, Miyawaki A, Matsumoto K, Mori I (2004) The C. elegans thermosensory neuron AFD responds to warming. Curr Biol 14:1291-1295.

Lee Y, Lee Y, Lee J, Bang S, Hyun S, Kang J, Hong ST, Bae E, Kaang BK, Kim J (2005) Pyrexia is a new thermal transient receptor potential channel endowing tolerance to high temperatures in Drosophila melanogaster. Nat Genet 37:305-310.

Liu L, Yermolaieva O, Johnson WA, Abboud FM, Welsh MJ (2003) Identification and function of thermosensory neurons in Drosophila larvae. Nat Neurosci 6:267-273.

Macdonald SS, Rako L, Batterham P, Hoffmann AA (2004) Dissecting chill coma recovery as a measure of cold resistance: evidence for a biphasic response in Drosophila melanogaster. J Insect Physiol 50:695-700.

Majercak J, Sidote D, Hardin PE, Edery I (1999) How a circadian clock adapts to seasonal decreases in temperature and day length. Neuron 24:219-230.

McClintock TS, Ache BW (1989) Histamine directly gates a chloride channel in lobster olfactory receptor neurons. Proc Natl Acad Sci USA 86:8137-8141.

Melzig J, Buchner S, Wiebel F, Wolf R, Burg M, Pak WL, Buchner E (1996) Genetic depletion of histamine from the nervous system of Drosophila eliminates specific visual and mechanosensory behavior. J Comp Physiol A Neuroethol Sens Neural Behav Physiol 179:763-773.

Melzig J, Burg M, Gruhn M, Pak WL, Buchner E (1998) Selective histamine uptake rescues photo- and mechanoreceptor function of histidine decarboxylase-deficient Drosophila mutant. J Neurosci 18:7160-7166.

Mizunami M (1995a) Neural organization of ocellar pathways in the cockroach brain. J Comp Neurol 352:458-468.

Mizunami M (1995b) Morphology of higher-order ocellar interneurons in the cockroach brain. J Comp Neurol 362:293-304.

Mori I (1999) Genetics of chemotaxis and thermotaxis in the nematode Caenorhabditis elegans. Annu Rev Genet 33:399-422.

Nässel DR (1999) Histamine in the brain of insects: a review. Microsc Res Tech 44:121-136.

O’Neill JW, Bier E (1994) Double-label in situ hybridization using biotin and digoxigenin-tagged RNA probes. Biotechniques 17: 870:874-875.

Overgaard J, Sorensen JG, Petersen SO, Loeschcke V, Holmstrup M (2005) Changes in membrane lipid composition following rapid cold hardening in Drosophila melanogaster. J Insect Physiol 51:1173-1182.

Pesah Y, Burgess H, Middlebrooks B, Ronningen K, Prosser J, Tirunagaru V, Zysk J, Mardon G (2005) Whole-mount analysis reveals normal numbers of dopaminergic neurons following misexpression of alphaSynuclein in Drosophila. Genesis 41:154-159.

Python F, Stocker RF (2002) Immunoreactivity against choline acetyltransferase, gamma-aminobutyric acid, histamine, octopamine, and serotonin in the larval chemosensory system of Drosophila melanogaster. J Comp Neurol 453:157-167.

Rosenzweig M, Brennan KM, Tayler TD, Phelps PO, Patapoutian A, Garrity PA (2005) The Drosophila ortholog of vertebrate TRPA1 regulates thermotaxis. Genes Dev 19:419-424.

Samuel AD, Silva RA, Murthy VN (2003) Synaptic activity of the AFD neuron in Caenorhabditis elegans correlates with thermotactic memory. J Neurosci 23:373-376.

Saper CB, Lu J, Chou TC, Gooley J (2005) The hypothalamic integrator for circadian rhythms. Trends Neurosci 28:152-157.

Sarthy PV (1991) Histamine: a neurotransmitter candidate for Drosophila photoreceptors. J Neurochem 57:1757-1768.

Sawyer LA, Hennessy JM, Peixoto AA, Rosato E, Parkinson H, Costa R, Kyriacou CP (1997) Natural variation in a Drosophila clock gene and temperature compensation. Science 278:2117-2120.

Sayeed O, Benzer S (1996) Behavioral genetics of thermosensation and hygrosensation in Drosophila. Proc Natl Acad Sci USA 93:6079-6084.

Sharma Y, Cheung U, Larsen EW, Eberl DF (2002) pPTGAL, a convenient Gal4 P-element vector for testing expression of enhancer fragments in Drosophila. Genesis 34:115-118.

Shaw PJ, Cirelli C, Greenspan RJ, Tononi G (2000) Correlates of sleep and waking in Drosophila melanogaster. Science 287:1834-1837.

Shreve SM, Kelty JD, Lee Jr RE (2004) Preservation of reproductive behaviors during modest cooling: rapid cold-hardening fine-tunes organismal response. J Exp Biol 207:1797-1802.

Sidote D, Majercak J, Parikh V, Edery I (1998) Differential effects of light and heat on the Drosophila circadian clock proteins PER and TIM. Mol Cell Biol 18:2004-2013.

Stuart AE (1999) From fruit flies to barnacles, histamine is the neurotransmitter of arthropod photoreceptors. Neuron 22:431-433.

Tracey Jr WD, Wilson RI, Laurent G, Benzer S (2003) painless, a Drosophila gene essential for nociception. Cell 113:261-273.

Zars T (2001) Two thermosensors in Drosophila have different behavioral functions. J Comp Physiol A Neuroethol Sens Neural Behav Physiol 187:235-242.

Zars T (2003) Hot and cold in Drosophila larvae. Trends Neurosci 26:575-577.

Zheng Y, Hirschberg B, Yuan J, Wang AP, Hunt DC, Ludmerer SW, Schmatz DM, Cully DF (2002) Identification of two novel Drosophila melanogaster histamine-gated chloride channel subunits expressed in the eye. J Biol Chem 277:2000-2005. 